NBER WORKING PAPER SERIES

\title{
HOW DOES HEALTH PROMOTION WORK? EVIDENCE FROM THE DIRTY BUSINESS OF ELIMINATING OPEN DEFECATION
}

\author{
Paul Gertler \\ Manisha Shah \\ Maria Laura Alzua \\ Lisa Cameron \\ Sebastian Martinez \\ Sumeet Patil \\ Working Paper 20997 \\ http://www.nber.org/papers/w20997 \\ NATIONAL BUREAU OF ECONOMIC RESEARCH \\ 1050 Massachusetts Avenue \\ Cambridge, MA 02138 \\ March 2015
}

Gertler and Shah led the analysis and drafting of this paper with support from the other authors. Patil led the India evaluation, Cameron and Shah led the Indonesia Evaluation, Alzua led the Mali evaluation and Martinez led the Tanzania evaluation. Ben Arnold, Berta Briceno, Jack Colford, Sebastian Galiani, Jack Molyneaux and Alex Orsla provided valuable inputs into the country evaluations. The authors also wish to thank Cameron Bresline, Pascaline Dupas, Josh Gruber and seminar participants at UC Berkeley, USC and the 2015 AEA meetings in Boston for helpful comments. The authors gratefully acknowledge financial support from the Water and Sanitation Program at the World Bank through a grant from the Bill and Melinda Gates Foundation. Lisa Cameron and Manisha Shah also acknowledge funding from the Australian Research Council, Grant No. DP0987011. The opinions expressed in this paper are those of the authors alone and do not necessarily represent the opinions of the organizations where they work or of the funders. The authors have no material or financial interests in the results or opinions expressed in the paper. The views expressed herein are those of the authors and do not necessarily reflect the views of the National Bureau of Economic Research.

NBER working papers are circulated for discussion and comment purposes. They have not been peerreviewed or been subject to the review by the NBER Board of Directors that accompanies official NBER publications.

(C) 2015 by Paul Gertler, Manisha Shah, Maria Laura Alzua, Lisa Cameron, Sebastian Martinez, and Sumeet Patil. All rights reserved. Short sections of text, not to exceed two paragraphs, may be quoted without explicit permission provided that full credit, including $(\subset$ notice, is given to the source. 
How Does Health Promotion Work? Evidence From The Dirty Business of Eliminating Open

Defecation

Paul Gertler, Manisha Shah, Maria Laura Alzua, Lisa Cameron, Sebastian Martinez, and Sumeet

Patil

NBER Working Paper No. 20997

March 2015

JEL No. I12,I15,O15

\begin{abstract}
We investigate the mechanisms underlying health promotion campaigns designed to eliminate open defecation in at-scale randomized field experiments in four countries: India, Indonesia, Mali, and Tanzania. Health promotion works through a number of mechanisms, including: providing information on the return to better behavior, nudging better behavior that one already knows is in her self-interest, and encouraging households to invest in health products that lower the marginal cost of good behavior. We find that health promotion generally worked through both convincing households to invest in in-home sanitation facilities and nudging increased use of those facilities.

We also estimate the causal relationship between village open defecation rates and child height using experimentally induced variation in open defecation for identification. Surprisingly we find a fairly linear relationship between village open defecation rates and the height of children less than 5 years old. Fully eliminating open defecation from a village where everyone defecates in the open would increase child height by 0.44 standard deviations. Hence modest to small reductions in open defecation are unlikely to have a detectable effect on child height and explain why many health promotion interventions designed to reduce open defecation fail to improve child height. Our results suggest that stronger interventions that combine intensive health promotional nudges with subsidies for sanitation construction may be needed to reduce open defecation enough to generate meaningful improvements in child health.
\end{abstract}

\author{
Paul Gertler \\ Haas School of Business \\ University of California, Berkeley \\ Berkeley, CA 94720 \\ and NBER \\ gertler@haas.berkeley.edu \\ Manisha Shah \\ Department of Public Policy \\ University of California, Los Angeles \\ Luskin School of Public Affairs \\ 3250 Public Affairs Building \\ Los Angeles, CA 90095-1656 \\ and NBER \\ manishashah@ucla.edu \\ Maria Laura Alzua \\ Universidad Nacional de La Plata \\ malzua@depeco.econo.unlp.edu.ar
}

\author{
Lisa Cameron \\ Monash University \\ Australia \\ and IZA \\ lisa.cameron@monash.edu \\ Sebastian Martinez \\ Inter American Development Bank \\ smartinez@iadb.org \\ Sumeet Patil \\ School of Public Health \\ University of California \\ Berkeley, CA 94720 \\ and NEERMAN, Mumbai \\ srpatil@neerman.org
}




\section{INTRODUCTION}

Much of health status is driven by individual choices over diet, exercise, hygiene and risk behaviors. However, successfully promoting healthy behavior has been notoriously difficult because existing (unhealthy) behaviors are deep-rooted habits that form early in life and are reinforced by cultural and social norms. Small monetary, time, and hassle costs can be enough to inhibit changing well-established habits even if such inert behavior is suboptimal (DellaVigna 2009; Sunskind and Thaler 2008). Despite vast investment in information and promotion campaigns, large numbers of people who know better continue to behave in ways that are detrimental to their long-term health such as smoking, consuming too much sugar, not washing their hands, substance abuse, open defecation, and risky sex.

There are two broad categories of interventions widely used to promote healthy behavior. The first subsidizes the purchase of health products, such as a water filters and insecticide treated bednets, that lowers the cost of healthy behavior and thereby makes the behavior more convenient (Dupas 2014b). ${ }^{1}$ Subsidies for health products are typically justified based on public goods arguments. Since the use of health products prevents parasitic and infectious diseases that would otherwise spillover into other households, private investment in health products is likely socially suboptimal. In addition, when the majority of the population is cash and credit constrained, subsidies may be needed to ensure the widespread adoption needed to prevent spillover.

The second category is health promotion campaigns aimed at behavioral change. These campaigns are the mainstay of public health interventions and typically combine information messaging with nudges such as helping develop specific plans, reminders, commitment devices

\footnotetext{
${ }^{1}$ A number of studies have looked at the effect of subsidies on take-up of health products and effect of having health products on behavior. For example, subsidies increase the uptake of toilets (Pattanayak et al., 2009). Having soap and hot water in the house lowers the cost of hand washing (Luby et al. 2004, Galiani et al 2014). Storing condoms on site lowers the cost of safe sex (Gertler et al 2005). Owning a bednet already treated with insecticide lowers the cost of malaria prevention (Cohen and Dupas 2010, Cohen et al 2014, Dupas 2014a, Tarozzi et al., 2014). Dispensing chlorine tablets at public water sources lowers the cost of accessing clean water (Ahuja et al, 2010). Owning a clean cook stove lowers the cost of reducing indoor air pollution (Bensch and Peters 2012, Levine et al. 2013).
} 
and financial incentives (e.g. Ashraf et al., 2006, Thaler and Sunstein, 2008, Giné et al., 2010, Karlan et al, 2012, Dupas and Robinson 2013). Examples include campaigns to reduce smoking and substance abuse cessation, as well as to improve nutrition and exercise, hygiene, safe sex, etc. Health promotion campaigns work through a number of mechanisms including providing information on the return to the behavior, nudging better behavior that one already knows is in her self-interest, and encouraging households to invest in health products that lower the marginal cost of good behavior.

The two approaches are based on very different views of the world. The subsidy approach argues that households want to engage in the healthy behavior but are liquidityconstrained so that they are not able to invest in the health products necessary to make the behavior convenient. Under this paradigm, once the family has invested in the health product, the lower cost of the healthy behavior will facilitate the desired change in behavior. In contrast, the health promotion approach considers that even if the behavior is convenient, individuals will only engage in the behavior if one can change deep-rooted habits and counter prevailing social norms. If the primary mechanism through which health promotion works is through encouraging investment in health products as opposed to overcoming norms and habits, then it may be more effective to simply subsidize the purchase of products, especially in the liquidity constrained cases where health promotion has limited effect on investment. However in cases where health product subsidies are not enough, behavioral change interventions may also be necessary and vice versa.

In this paper we report on the effects and mechanisms (behavioral change versus investment) of health promotion campaigns designed to eliminate open defecation in at-scale randomized field experiments from four countries: India, Indonesia, Mali, and Tanzania. The field experiments are at-scale in the sense that the interventions were designed and implemented by governments as part of their national environmental health strategies, and randomly rolled out geographically over time. The combination of at-scale cluster randomized field experiments with common measurement of outcomes in four countries provides not only strong internal validity but also a degree of external validity not seen in most studies. 
Open defecation (OD) is thought to be a major cause of the persistent worldwide burden of diarrhea and enteric parasite infection among children under 5 years old (Mara et al., 2010). Open defecation can lead to the fecal contamination of water and food supplies and to the transmission of soil-borne helminthes (Chavasse et al., 1999). Reducing open defecation requires access to and use of improved sanitation facilities, which are defined as facilities that prevent human feces from re-entering the environment. In $2010,47 \%$ of the world population did not have access to onsite improved sanitation facilities (UNICEF-WHO, 2012). Observational studies of interventions that prevent human feces from entering the environment have been shown to reduce diarrheal disease (Clasen et al., 2010, Norman et al., 2010), enteric parasite infections (Barreto et al., 2010, Ziegelbauer et al., 2012), and child stunting and mortality (Checkley et al. 2004 and 2008, Humphrey 2009, and Spears 2012).

Given the large externalities associated with open defecation, families are only fully protected if both they and their neighbors have access to and use improved sanitation facilities. This has led to interventions that focus on the open defecation practices of the community, rather than solely of the household. The most popular intervention is Community-Led Total Sanitation (CLTS), which informs communities and helps them to develop plans and commitments to become $100 \%$ open defecation free (Kar and Pasteur 2005; Kar and Chambers, 2008). CLTS is intended to be participatory in nature and facilitates communities to take a decisive role in ensuring that each and every member internalizes the implication of open defecation (Sah \& Negussie, 2008). Pioneered in Bangladesh in 1999, CLTS has been implemented throughout Asia, Latin America, and Sub-Saharan Africa (Wells and Sijbesma, 2012). Despite this, a number of recent experimental reduced form studies have found mixed results on the impact of CLTS on child health outcomes (Clausen et al. 2014; Dickerson et al. 2014; Hammer and Spears 2103; Patil et al. 2014; and Wells and Sijbesma, 2012).

While CLTS was the common core intervention in all four countries under study in this paper, there were a number of important variations and additions. Indonesia, India, and Tanzania additionally strengthened the private market availability of trained masons and construction materials. The World Bank refers to the combined CLTS and strengthened private sanitation market approach as Total Sanitation and Sanitation Marketing (TSSM) campaigns. 
India's Total Sanitation Campaign (TSC) combined TSSM with additional subsidies for private inhome sanitation construction (toilet or latrine). While Mali was a pure CLTS intervention, it was much more intensive than in the other countries, as they conducted 12 monthly visits compared to the usual initial visit plus one follow-up. The interventions are described in greater detail in Section 2.

The data used in this paper are generated from cluster-randomized interventions in all four countries, where the unit of randomization is the village. In general, the samples for all four countries are well balanced at baseline, have low levels of attrition, and show little evidence of attrition bias. The details of the random assignment and sample are summarized in Table 1 and discussed in detail in the data appendix.

In Section 3 we derive an expression that decomposes the reduced form program impact on open defecation into three terms: (1) investment in private in-home sanitation facilities, (2) change in the open defecation behavior of families that have private in-home sanitation faculties, and (2) change in the behavior of families that do not have private in-home sanitation faculties and must use shared facilities. We then use the data from the field experiments to estimate each of the terms in the decomposition.

The results suggest that the health promotion interventions produced significant reductions in household and village open defecation rates in all four countries -- but to varying degrees. The Mali intervention saw the largest reduction in open defecation; close to 3-times the reduction of the next closest country. Moreover, Mali is the only country in which the intervention succeeded in reducing open defecation by both households that did and households that did not have private in-home sanitation facilities at baseline. In the other three countries, all of the behavioral change (reductions in open defecation) occurred exclusively in the households that did not have private sanitation facilities at baseline. The more effective results in Mali are likely due to the much more intensive CLTS intervention compared to the other countries.

In Indonesia, Mali, and Tanzania, the health promotion campaigns worked both through getting households to invest in in-home private sanitation facilities and through increased use 
of private and shared sanitation facilities. However, in India, which combined a very light CLTS with large subsidies for sanitation facility construction, all of the reduction in open defecation was through the investment channel. Interestingly, households used new private in-home sanitation facilities less in countries where they were induced to build through the behavioral change components of CLTS (i.e. Indonesia, Mali, and Tanzania) compared to India, where they were induced to build through subsidies.

In Section 4, we use experimentally induced variation in village OD rates to identify the causal relationship between OD and child height. Surprisingly we find a fairly linear relationship. We estimate that fully eliminating open defecation from a village where everyone defecates in the open would increase child height by 0.44 standard deviations. Hence modest to small reductions in open defecation are unlikely to have a significant effect on child height and explain why many health promotion interventions designed to reduce open defecation fail to improve child height. Our results suggest that stronger interventions that combine intensive health promotional nudges with subsidies for sanitation construction may be needed to reduce open defecation enough to generate meaningful improvements in child health.

In the final section we use the results from the decomposition analysis to discuss how interventions might be constructed to achieve large enough reductions in village open defecation to generate meaningful improvements in child health. By far the biggest reductions in open defecation come from households constructing private sanitation facilities. Installing private sanitation has a much larger effect on open household defecation than any of the behavioral change pathways. However, the effect on village open defection rates depends on existing village-level private sanitation coverage. Households may need substantial subsidies and the effect of subsidies on village private sanitation coverage depends on the price elasticity of demand. Even with very large subsidies, the evidence suggests that subsidizing private sanitation construction by itself will not achieve sufficient reductions in village-level open defection rates to be able to produce meaningful improvements in health outcomes. However, it might be possible to achieve such levels by combining the intensive CLTS Mali model with subsidies. 


\section{INTERVENTIONS}

The core intervention in all four countries was CLTS. ${ }^{2}$ CLTS programs are communitytargeted and community-driven participatory campaigns designed to promote and improve sanitation practices in rural areas (Kar and Chambers, 2008). External facilitators are sent to villages for a few days to lead graphic discussions of the community's current sanitation practices, the health consequences of such practices, and to facilitate collective action plans to eliminate open defecation. The facilitated discussions are held in public places and are open to all community members. They involve a "walk of shame," where villagers are asked to provide a tour indicating where people defecate. A map of the village is drawn on the ground and villagers are asked to indicate where they live, where they defecate, and the routes they take there and back. The facilitator then helps people analyze how fecal contamination is spreading from the exposed excreta to their living environments and food and drinking water. It soon becomes apparent that everyone is ingesting small amounts of each other's feces. The premise underlying the program approach is that this process prompts feelings of disgust that leads to personal and collective desire to solve the problem with the ultimate aim of becoming an Open Defecation Free (ODF) community. The community then is on its own to forge its own plan of action with, at best, limited support from the program. The external facilitators somtimes continue make followup visits to keep the community motivated and monitor their progress to become the ODF community.

One of the key aspects of CLTS is to encourage households in the community to build and use sanitation facilities that prevent fecal matter from re-entering the environment and flies from transmitting pathogens from the fecal matter to food and water that are later ingested. While CLTS derived solutions could involve building shared toilets or public toilets, in practice the main outcome has been to construct private in-home, water-flushed squat toilets with drainage to a sealed pit. Households and communities are typically left to their own

\footnotetext{
${ }^{2}$ Detailed information on the interventions and experimental designs can be found in in Cameron and Shah (2010) and Cameron et al. (2013) for Indonesia TSSM, in Patil et al. (2013) for India TSC, f in Alzua et al. (2014) or Mali, and in Briceño et al. (2014) for Tanzania.
} 
devices to finance and implement the construction of these facilities, as CLTS by itself typically does not provide resources for this purpose.

While CLTS was the common intervention, there were a number of differences across the four countries (See Table 2). Indonesia, India, and Tanzania also included capacity building of sanitation entrepreneurs in order to insure that households who want to build private inhome sanitation faculties are able to purchase the materials (i.e. cement) and hire trained masons to assist in the construction (supply side). India additionally provided monetary subsidies to households for the construction of private in-home sanitation facilities (demand side). The amount of the Indian subsidy depends on whether a household was defined to be Below Poverty Line (BPL) or Above the Poverty Line (APL). The program provided materials and cash of Rs 4200 to Rs4700 (US \$84 to \$144) to BPL households and Rs 2000 to Rs 5000 (US \$40 to $\$ 100)$ to non-BPL households to support toilet construction. Finally, there were substantial differences in the intensity of the CLTS. In Mali, facilitators visited communities first for CLTS triggering and then monthly for one year to monitor activities and reinforce CLTS messaging. In contrast, in Indonesia and Tanzania facilitators visited the communities only twice, once for a triggering visit with a second follow-up visit shortly thereafter to reinforce CLTS messaging. India had the lightest CLTS intensity with only one visit for triggering and almost no follow-up.

Compliance with the experimental design was not perfect (Table 1). In Indonesia, only $66 \%$ of the villages assigned to treatment were triggered through CLTS activities (compliance), while $14 \%$ assigned to the control group also received the intervention (contamination). Similarly, $25 \%$ of the villages in India and $10 \%$ in Mali assigned to the control group received treatment. In the analyses below, we compare the outcomes of the group assigned to treatment to the group assigned to control and therefore the results are interpreted as intentto-treat estimates.

\section{OPEN DEFECATION}

In this section we lay out a framework that decomposes the impact of a health promotion intervention on OD into the contributions of behavioral and investment pathways. 
We then estimate the parameters of the decomposition and use those estimates to assess the relative contribution of each pathway.

\subsection{Conceptual Framework}

We begin by noting that an intervention differentially affects those households that have and those that do not have existing private in-home sanitation facilities. For households that have existing private sanitation facilities in their house, the only pathway is through behavioral change, i.e. increased use of those facilities. In the case of families that do not have existing private in-home sanitation, an intervention can increase the use of shared (public or private) facilities outside the house or cause households to invest in private in-home sanitation. The investment reduces the time and hassle or "transaction" cost of using sanitation facilities, thereby increasing use of sanitation facilities.

We formalize this discussion as follows. Let $\pi(O D)$ be the probability of open defecation and $\pi(S)$ be the probability of having private in-home sanitation facilities. Then the probability of open defecation can be written as the weighted sum of the conditional OD probabilities of those with and without private in-home sanitation facilities:

$$
\pi(O D)=\pi(O D \mid S=1) \pi(S)+\pi(0 D \mid S=0)[1-\pi(S)]
$$

In (1), $\pi(O D \mid S=1)$ is the probability of $O D$ conditional on having private in-home sanitation facilities, and $\pi(O D \mid S=0)$ is the probability of $O D$ conditional on not having private in-home sanitation facilities.

We obtain an expression of the pathways through which an intervention affects OD by totally differentiating (1) and collecting terms:

$$
\begin{gathered}
d \pi(O D)=d \pi(O D \mid S=1) \pi(S)+d \pi(O D \mid S=0)[1-\pi(S)]+ \\
d \pi(S)[\pi(O D \mid S=1)-\pi(O D \mid S=0)]
\end{gathered}
$$

The change in the OD rate, then, is the weighted sum of the change in OD of those that have private sanitation and those that do not have private sanitation, plus the change in the share that have private sanitation, times the difference in OD of those that do and do not have 
private sanitation. The first two terms are the behavioral pathways and the third term is the investment in reducing the cost of access to sanitation facilities.

We convert the decomposition into the share of the total change in OD accounted for each of the three pathways by dividing both sides of (2) by $d \pi(O D)$ :

$$
\begin{gathered}
1=\frac{d \pi(O D \mid S=1) \pi(S)}{d \pi(O D)}+\frac{d \pi(O D \mid S=0)[1-\pi(S)]}{d \pi(O D)}+ \\
\frac{d \pi(S)[\pi(O D \mid S=1)-\pi(O D \mid S=0)]}{d \pi(O D)}
\end{gathered}
$$

\subsection{Total Impact and Behavioral Change With Existing Private In-Home Sanitation}

We obtain $d \pi(O D)$ and $d \pi(O D \mid S=1)$ in equation (2) by estimating the following regression for all households, and for households that have existing private in-home sanitation facilities at baseline respectively:

$$
O D_{i j k}=\alpha+\beta T_{j k}+\sum_{k} \gamma_{k} R_{k}+\epsilon_{i j}
$$

where $O D_{i j k}$ is the OD rate of household $i$ in village $j$ in randomization strata $k, T_{j}$ takes on the value one if village $j$ in randomization strata $k$ was assigned to treatment, and $R_{k}$ takes on the value one if village $j$ was in stratum $k$.

The parameters in (3) are identified off the random assignment using the endline data. The samples are well balanced across control and treatment groups for all households as well as for the sub-samples of households with existing in-home sanitation facilities and for those that do not have private facilities (Appendix Tables A1-A4). The estimates are intent-to-treat (ITT) parameters that compare the outcomes of households in those villages to which the program was assigned to be offered with control villages that were assigned not to be offered the program. We cluster the standard errors at the village level.

The dependent variable is an intensity measure of open defecation. The household was asked separately for men, women, and children if they defecated in the open always, sometimes, or never. We coded the answers 2 for always, 1 for sometimes, and 0 for never. 
We then summed the answers for the 3 types of household members. The values ranged from 0 to 6 . We then divided by 6 in order to obtain a measure of OD intensity between 0 and 1 , where 0 indicates no open defecation and 1 indicates always open defecate.

Table 3 presents the estimates of the impact of the program on households' defecation behavior for Indonesia, India, Mali, and Tanzania. The first column reports estimates of $d \pi(D)$, the impact of treatment on open defecation for all households. We find negative effects in all four countries, of which three are statistically significant at conventional levels. The largest effects are in Mali where the CLTS nudging was the most intensive. There we find that the OD rate fell by 0.33 , which, when compared to the control group means, amounts to a $58 \%$ reduction in overall OD. Next highest is Tanzania where OD rates fell by 0.13 , a $54 \%$ reduction in OD compared to the control group. The relative effects in Mali and Tanzania are about the same because the OD rate in the control group in Tanzania (0.23) is less than half of that in Mali (0.57). In India and Indonesia the effects sizes are substantially smaller at less than $10 \%$.

In the second column of Table 3 we report the results for the sample of households that had private in-home sanitation at baseline, which provides us with estimates of $d \pi(O D \mid S=1)$. In 3 out of the 4 countries, there was effectively no impact of treatment on the OD rates of households that had existing in-home private sanitation faculties. In Indonesia and Tanzania, this effect is most likely driven by the very low OD rates among these households to begin with. However, the OD rates among households with existing private sanitation are nontrivial in India and Mali. While treatment had a large negative effect on this group in Mali, it had no impact in India. This is consistent with the more intensive behavioral change intervention in Mali compared to India.

Finally, in the last column we report estimates for those households that did not have private in-home sanitation facilities at baseline. These estimates are a combination of the investment effect and the increased use of shared non-private sanitation facilities among those who chose not to construct. While not providing information for the decomposition in equation (2), the results are interesting because, except for Mali, almost all of the overall reduction in OD comes from these households. In all countries, the estimated treatment effects are substantially larger than those for households with existing private in-home sanitation facilities. 
The treatment effect on households with no private sanitation is a reduction in open defecation by $10 \%$ in Indonesia, $8 \%$ in India, $57 \%$ in Mali, and $45 \%$ in Tanzania.

\subsection{Investment in Sanitation Facilities}

We obtain $d \pi(S)$ from the following regression specification using endline data for households that did not have existing private in-home sanitation facilities at baseline:

$$
S_{i j k}=\alpha+\beta T_{j k}+\sum_{k} \gamma_{k} R_{k}+\epsilon_{i j}
$$

where $S_{i j k}$ takes on the value 1 if household $i$ in village $j$ in randomization strata $k$ has access to sanitation facilities at endline. We consider three sanitation outcomes including (i) access to any sanitation facilities, (ii) access to private in-home facilities and (iii) access to shared or public facilities outside the home. The estimate $d \pi(S)$ is the impact of treatment on private inhome facilities. Again, the estimates in (4) are identified off the random assignment for the sample of households that did not have private in-home sanitation facilities at baseline, are intent-to-treat (ITT) parameters, and the standard errors are clustered at the village level.

The first column of Table 4 reports estimates the impact of treatment on access to any sanitation facilities. We see statistically significant positive effects in all 4 countries. Again, the largest impact is in Mali where sanitation access increased by 39 percentage points, an increase of $267 \%$ over the control group. The next highest impact was in India where access increased by 21 percentage points, an increase of $166 \%$ over the control group. The impacts of treatment on access in Indonesia and Tanzania were more modest amounting to $47 \%$ and $19 \%$ increases, respectively. Except in Indonesia, all of the increases in access to sanitation came through construction of private in-home sanitation facilities. In Indonesia about half of the increase in sanitation access came from expanded use of shared out-of-home facilities.

\subsection{Behavioral Change Without Existing Private In-Home Sanitation}

Finally, we turn to estimating the remaining two parameters associated with those that did not have private in-home sanitation facilities at baseline. The first, $d \pi(O D \mid S=0)$, is the impact of treatment on the use of shared out-of-home facilities, and the second, 
$[\pi(O D \mid S=1)-\pi(O D \mid S=0)]$, is the impact of installing private in-home sanitation facilities on OD.

We estimate these parameters using the regression specified below for the sample households that did not have private in-home sanitation facilities at baseline: ${ }^{3}$

$$
O D_{i j k}=\lambda_{0}+\lambda_{1} T_{j}+\lambda_{2} S_{i}+\lambda_{3} T_{j} S_{i}+\sum_{k} \gamma_{k} R_{k}+\varepsilon_{i j k}
$$

where $S_{i}$ is an indicator of having private in-home sanitation facilities at endline. The coefficient on treatment, $\lambda_{1}$, is an estimate of the difference in OD of families that do not have private inhome sanitation facilities in treatment versus control communities and is our estimate of $d \pi(O D \mid S=0)$. The coefficient on $S_{i}, \lambda_{2}$, is an estimate of the difference in OD of families that build sanitation facilities to those that do not in control communities. And the coefficient on the interaction of treatment and sanitation facilities, $\lambda_{3}$, is an estimate of the difference in OD of families that build sanitation facilities in treatment versus control communities. Hence, our estimate of $[\pi(O D \mid S=1)-\pi(O D \mid S=0)]$ is $\lambda_{2}+\lambda_{3}$.

Unlike the previous estimates, the parameters in (5) are not identified purely off the randomized experiments. A major concern is that private in-home sanitation construction is a choice and might be correlated with other characteristics that also drive open defecation such as wealth, education and preferences for hygiene and health. To investigate how much other characteristics might be driving our results, we estimate a second set of models that include a series of variables measured at baseline to control for differences in wealth, education and preferences. In all 4 countries we control for the head's years of schooling, family composition, knowledge that open defecation causes diarrhea, whether the household believes open defecation is acceptable, income or wealth per capita, and for Indonesia we additionally control for risk preferences and time discount rates. The detailed list of control variables for each country is listed in the table notes of Table 5.

\footnotetext{
${ }^{3}$ This specification is essentially a version of the Blinder (1973) and Oaxaca (1973) decomposition of a treatment effect into its pathways.
} 
We report results from the estimation of equation (5) without any controls in Panel A and with controls Panel B in Table 5. We note that the point estimates are almost identical in the models and without controls allowing us to cautiously interpret these estimates as causal.

The first parameter of interest is the coefficient on treatment, $\lambda_{1}$, which is the estimate of $d \pi(O D \mid S=0)$. The coefficient is negative and statistically significant in 3 out of four countries consistent with treatment increasing the use of shared sanitation facilities outside of the home. However, the estimated effect in Mali is substantially larger than in the other countries consistent with the behavioral change intervention being substantially more intensive in Mali compared to the other countries. Only in India was there no effect on the defecation practices of family without private facilities again consistent with the fact that public or community toilets were not constructed, the behavior change and subsidies both focused on building and using in-home private toilets.

The coefficient on $S_{i}, \lambda_{2}$, is negative, large, and statistically significant in all 4 countries. The point estimates are large suggesting that the installation of in-home sanitation facilities greatly reduces OD. Lowering the time and hassle cost of use of sanitation facilities greatly reduces open defecation. In 3 out of the four countries the point estimates are very similar; The installation of private in-home sanitation facilities reduces OD rates by about 0.3. In Indonesia, the point estimate is about twice the effect in the other countries.

The coefficient on the interaction of treatment and $S_{i}, \lambda_{3}$, is positive and statistically significant in Mali. In addition, though not statistically significant, it is positive and non-trivial in Indonesia and Tanzania. Only in India is the coefficient both not statistically significant and small in magnitude. The largest effect $(0.15)$ is in Mali, which had the strongest behavioral CLTS intervention followed by Indonesia (0.11) and Tanzania (0.06), which had a weaker behavioral CLTS intervention and combined CLTS with improvements in the supply of sanitation installation. The smallest effect was in India (0.001), which combined the weaker CLTS approach with large subsidies for sanitation installation. This suggests that households that were convinced by the CLTS health promotion to install private in-home sanitation facilities use them less than those who installed them without the nudge, whereas there is no difference in use when subsidies were the primary incentive to install the facilities. 


\subsection{Decomposition}

We now use these parameter estimates to decompose the change in open defecation into the following behavioral and investment pathways based on equation (2):

(i) $d \pi(O D \mid S=1)[\pi(s)]$ = change in OD by those with private in-home sanitation facilities (behavioral)

(ii) $d \pi(O D \mid S=0)[1-\pi(s)]=$ change in OD by those without private in-home sanitation facilities (behavioral)

(iii) $d \pi(S)[\pi(O D \mid S=1)-\pi(O D \mid S=0)]=$ change in OD due to investment in private in-home sanitation facilities (investment)

The decomposition results are presented in Table 6 . In 3 out of 4 countries, the behavioral pathways (i.e. increased used of sanitation facilities) accounted for more than half of the reduction in open defection obtained from the intervention. Only in India was all of the change (100\%) due to investment in private in-home sanitation facilities. This is likely due to the fact that India is the only country that had subsidies for construction.

In the 3 countries where behavioral change was important, only in Mali was there a significant behavioral change among those who had private in-home sanitation facilities, while in Indonesia and Tanzania the behavioral change was concentrated in households without inhome facilities by increasing use of shared out-of-home sanitation facilities. This is consistent with the fact that the CLTS component was much more intensive in Mali compared to the other countries.

\section{CHILD HEALTH}

Promotion of healthy behaviors and in particular reducing open defecation is designed to improve health outcomes. Open defecation leads to the fecal contamination of water and food supplies and to the transmission of soil borne helminthes (Chavasse et al., 1999). Gastrointestinal pathogenic infections consume micronutrients, cause diarrhea, and reduce the absorption of nutrition in general, leading to retarded growth and development in young children. 
In this section, we assess the extent to which reductions in open defecation improved child health outcomes measured by height of children less than 5 at endline, an age at which height is sensitive to parasitic infections, diarrhea, and illness in general. We construct heightfor-age z-scores, which place the child's height in the distribution of a well-nourished reference population for her age. We use a standardized age- and gender-specific growth reference based on WHO standards $(2006,2007)$.

We measure $O D$ at the village level rather than at the household level since a family's protection from the pathogens spread through OD depends on both their own behavior and the behavior of their neighbors. Eliminating their own OD will have limited protection if their neighbors continue to practice OD.

\subsection{Empirical Specification}

Our empirical approach is based on the health capital model originally proposed in Grossman (1972) that specifies health as stock that accumulates as a function of investment:

$$
H_{t}=I_{t}+(1-\delta) H_{t-1}+\varepsilon_{t}
$$

In (6) $H_{t}$ is the stock of health capital in period $t, I_{t}$ is investment in health capital such as nutrition, prevention and curative medical care, and prevention activities such as exercise, safe water and sanitation; $\delta$ is the depreciation rate, and $\varepsilon_{t}$ is a shock to health in period $t$.

The general approach will be to replace $I_{t}$ with measures of village levels of OD and estimate an equation of the following form:

$$
H_{i j t}=\alpha+\beta O D_{j t}+\gamma H_{i j t-1}+\varepsilon_{i j t}
$$

Where $O D_{j t}$ is the open defecation rate in village $j$ in period $t$. By conditioning on lagged $H_{t-1}$, $\beta$ is interpreted as the effect of village OD on child growth between the 2 periods.

\subsection{Variation in Village Open Defecation Rates}

In the analysis above we demonstrated at the household level that the effect of treatment on household level OD depends on whether the household had private in-home 
sanitation at baseline. Therefore, the effect of treatment on village OD rates should vary depending on village private sanitation coverage at baseline.

Figure 1 presents the distributions of village-level private sanitation rates at baseline and shows substantial heterogeneity both within and between countries. We restrict this analysis to the 3 countries for which we have data on child height both at baseline and followup: India, Indonesia and Mali. India had by far the lowest baseline sanitation coverage, with the majority of villages having less than $20 \%$ of households with private sanitation. Indonesia had the highest coverage rates, with Mali in between India and Indonesia.

The difference in baseline village sanitation did indeed result in substantial heterogeneity in village-level OD rates. In Figure 2, we present the distributions of village-level OD rates by treatment and control groups. Overall in Panel $A$, there was a substantial shift in villages from the top 3 quintiles to the bottom two quintiles and especially to the lowest quintile in OD rates. In India (Panel B), the shift was from the highest quintile to the middle quintile. In Indonesia (Panel C), the shift was from middle 3 quintiles to the lowest quintile. Finally, in Mali (Panel D), the shift was from the top 3 quintiles to the bottom 2 quintiles.

\subsection{The Impact of Village Open Defection on Child Height}

In this section we estimate the causal relationship between village OD and child height exploiting the experimentally induced variation in village OD for identification. To do so, we pool the data from the 3 countries for which we have data on child height both at baseline and follow-up: India, Indonesia and Mali. The analysis sample includes 5600 observations from 318 villages.

We first estimate the association between child height z-scores and village-level OD non-parametrically using Lowess regression (Figure 3). The relationship is negative, i.e. height for age z-scores fall as the village OD rises, and the 95-degree confidence regions are very tight. Remarkably, the relationship appears to be linear suggesting that there is no threshold that needs to be achieved to obtain health benefits.

We estimate (7) by IV GMM using the pooled data both with and without individual and household socio-economic controls. The individual and household level controls are entered as 
interactions with an indicator variable for the country in which the child lives. We instrument for $O D_{j t}$ using randomized treatment assignment status of the village and an interaction of assignment status and the baseline level of in-home sanitation coverage in the village; i.e. the share of households that had private in-home sanitation facilities at baseline. From the analysis above the overall effect of treatment on households varies by whether the household had sanitation at baseline. Therefore, the effect of treatment on village OD should vary by the share of households that had sanitation facilities at baseline. Again, we interact the instruments with country indicators, thus giving us 6 instruments.

The results are reported in Table 7. The estimated effects are statistically significant for all of the models. The Kleeberg-Pop F-statistics from the first stage are large and the instruments are statistically significant for 5 out of the 6 variables (Panel B). Interestingly, the IV estimates of the effect of Village OD on height are relatively close in magnitude to the OLS estimates (Panel A). In addition, while adding controls lowers the estimated impact, the reduction is relatively small. The estimated slope means that fully eliminating OD in a village where everyone practices OD would be associated with a 0.44 standard deviation increase in height. Another way to interpret the results is a one standard deviation reduction in the open defecation index (0.47) would yield about a 0.22 standard deviation increase in height.

The results have different implications for each of the countries depending on baseline OD rates. The biggest potential gains are in India where baseline village OD rates are 0.86 . In this case, reducing OD by half would yield about a 0.4 standard deviation in height. In Indonesia and Mali, where baseline village OD rates are 0.41 and 0.56 respectively, one would have to virtually eliminate OD to achieve similar levels of improvement in height. Finally, even though it was not included in the estimation, eliminating OD in Tanzania would yield at best modest gains in height as baseline village OD rates are only 0.23.

\subsection{Average Treatment Effects}

The above results explain in part the mixed results of the estimates of average treatment effects of CLTS based interventions on child height in the literature. We estimate the average treatment effects of the interventions on height using a version of equation (6) where 
the investment is the reduction in open defecation at the village level generated by the interventions.

$$
H_{i j t}=\alpha+\beta T_{j t}+\gamma H_{i j t-1}+\varepsilon_{i j t}
$$

Where $T_{j t}$ takes on the value one if village $j$ received the intervention in period $t$. In this case, $\beta$ is the ITT estimate of the impact of treatment in child height.

In Table 8 we present the results. The estimated average treatment effects on height in India and Indonesia were small and not significant, whereas in Mali the estimated effect size is 0.17 standard deviations. In India, Indonesia and Tanzania the interventions reduced average village $O D$ rates by $0.03,0.09$ and 0.12 respectively; not enough to achieve measureable improvements in height. In contrast in Mali, the average treatment effect on OD is 0.33 , close to 3-times higher than any of the other countries.

\section{DISCUSSION}

This paper examines the extent to which health promotional nudges work through investment in health products that lower the marginal cost of good behavior or through behavioral change using those products more than otherwise. The results address whether subsidies for health products are enough or whether nudges to use health products are necessary to change behavior sufficiently to improve health outcomes. Subsidies would be sufficient if households are simply liquidity constrained and have been unable to save enough or borrow to be able to build toilets. However, if open defecation is a deep-rooted habit that is culturally acceptable, then simply encouraging people to build toilets may not be enough to get people to use them.

We reported on the effects and mechanisms of health promotion campaigns designed to eliminate open defecation in at-scale randomized field experiments in 4 countries: India, Indonesia, Mali, and Tanzania. The field experiments are at-scale in the sense that the interventions were designed and implemented by governments as part of their national environmental health strategies, and randomly rolled out geographically over time. The 
combination of at-scale randomized field experiments in 4 countries provides not only strong internal validity but also a degree of external validity not seen in most studies.

We find evidence that in 3 of the 4 countries a large portion of the reduction in open defecation came through behavioral change, i.e. increased use of sanitation facilities, as opposed to investing in in-home sanitation facilities. The more intensive the health promotion the larger was the behavioral mechanism relative to the investment mechanism. Interestingly, households used new private in-home sanitation facilities less in countries where they were induced to build through shaming than in countries where they were induced to build through subsidies. Only in India, where the primary intervention was subsidies for construction of inhome facilities, was all of the effect achieved through investment. These results suggest that there may be gains to combining behavioral nudges on top of health product subsidies and that the intensity of the nudge is important.

Despite all interventions reducing open defecation, it does not appear that most of the interventions were, on average, strong enough to be able improve child health. Only the Mali intervention is significantly associated with a 0.17 standard deviation increase in height and the Mali intervention had close to 3-times the effect on open defecation than the next most effective intervention.

In order to assess the magnitudes of reductions in OD needed to achieve meaningful improvements in child health, we pooled the data and estimated the relationship between village-level $O D$ and child height using experimentally induced variation in the data to identify the causal relationship. We estimated that completely eliminating OD from a village in which everyone defecated in the open would result in a 0.44 standard deviation increase in height.

There are a number of important conclusions from this analysis. First of all, reductions in village-level OD do indeed seem to lead to improved child height. Second, reductions in OD in villages that have relatively low levels of OD are not only going to be hard to achieve but are unlikely to have an impact on health. Third, the small to modest reductions in OD generated from the interventions in India, Indonesia and Tanzania were not large enough to generate meaningful improvements in health. Hence, the interventions need to be strengthened in 
order to reduce village OD enough to have meaningful effects on child health. The question then is what types of interventions are strong enough.

The biggest reductions in village OD come from expanding sanitation coverage. Therefore, targeting interventions to villages with low private sanitation coverage has the greatest potential. However, the expansion of private sanitation is not enough by itself to have a meaningful effect on height. Take-up of private sanitation reduces household OD rates by 0.29 in Mali, 0.36 in Tanzania, 0.37 in India, and 0.61 in Indonesia. This means that, except in Indonesia, going from zero to $100 \%$ sanitation coverage would still lead to a less than 0.2 standard deviation improvement in height. However, except in India, most villages already have substantial sanitation coverage implying that the potential gains from increases in sanitation coverage are substantially lower.

Moreover, how one promotes sanitation expansion is important. It appears that households that are encouraged through the health promotion into installing sanitation facilities use them less than households who build them through subsidies. Hence, subsidies appear to be a more effective method of promoting households to use private sanitation than behavior change.

While expanding private sanitation facility installation is a critical step, it is not enough to achieve meaningful improvements in health outcomes. Our results do suggest however, that combining subsidies with intensive CLTS or another behavioral change intervention could be effective. The behavioral effects in Mali showed a substantial increase in the use of sanitation among those who had sanitation facilities. Specifically, in Mali the intervention led to a reduction in OD of 21 percentage points among those that had private sanitation facilities at baseline. Combining this with a large expansion of sanitation facilities from subsidies could generate sufficiently large reductions in village OD to achieve meaningful improvements in health outcomes. Whether this approach is cost-effective depends in large part on the price elasticity of the demand for sanitation facilities. 


\section{REFERENCES}

Ahuja, Amrita, Michael Kremer, and Alix Peterson Zwane. 2010. Providing Safe Water: Evidence from Randomized Evaluations. Annual Review of Resource Economics 2: 237-256.

Alzua ML, Coulibally, M., Djebarri Habiba, Osbert, N and Pickering A. (2014), " Final report: Impact evaluation of community-led total sanitation (CLTS) in rural Mali", Working Paper.

Ashraf, N., Karlan, D., and Yin, W. (2006). "Tying Odysseus to the Mast: Evidence from a Commitment Savings Product in the Philippines (May 2006) Quarterly Journal of Economics, 121(2), pp. 635-672.

Barreto ML, Genser B, Strina A, Teixeira MG, Assis AMO, et al. (2010) Impact of a city-wide sanitation programme in Northeast Brazil on intestinal parasites infection in young children. Environ Health Perspect. http://www.ncbi.nlm.nih.gov/pubmed/20705544.

Bensch, Gunther, and Jörg Peters. 2012. "A Recipe for Success? Randomized Free Distribution of Improved Cooking Stoves in Senegal." Working Paper.

Blinder, A.S. (1973) "Wage Discrimination: Reduced Form and Structural Estimates," Journal of Human Resources, University of Wisconsin Press, 8(4): 436-455.

Briceño, B., C. Aidan, and S. Martinez (2014). Promoting Handwashing and Sanitation: A Crossover Randomized Experiment in Rural Tanzania. Washington, DC: Water and Sanitation Program, World Bank.

Cameron, L. and Shah, M. (2010). Scaling Up Rural Sanitation: Findings from the Impact Evaluation Baseline Survey in Indonesia. Washington, DC: Water and Sanitation Program, World Bank.

Cameron, L, Shah, M. and S. Olivia (2013). Impact Evaluation of a Large-Scale Rural Sanitation Project in Indonesia. World Bank Policy Research Working Paper 6360.

Chambers, R. (2009) "Going to Scale with Community-Led Total Sanitation: Reflections on Experience, Issues and Ways Forward", IDS Practice Paper 1, University of Sussex', Brighton, UK: Institute of Development Studies

Chavasse DC, Shier RP, Murphy OA, Huttly SR, Cousens SN, et al. (1999) Impact of fly control on childhood diarrhoea in Pakistan: community-randomised trial. Lancet 353: 22-25.

Clasen TF, Bostoen K, Schmidt W-P, Boisson S, Fung IC-H, et al. (2010) Interventions to improve disposal of human excreta for preventing diarrhoea. Cochrane Database Syst Rev 6: CD007180.

Checkley W, Buckley G, Gilman RH, Assis AM, Guerrant RL, et al. (2008) Multi-country analysis of the effects of diarrhoea on childhood stunting. Int J Epidemiol 37: 816-830. doi:10.1093/ije/dyn099. 
Checkley W, Gilman RH, Black RE, Epstein LD, Cabrera L, et al. (2004) Effect of water and sanitation on childhood health in a poor Peruvian peri-urban community. Lancet 363: 112-118.

Cohen, Jessica and Pascaline Dupas (2010). "Free Distribution or Cost-Sharing? Evidence from a randomized malaria experiment". Quarterly Journal of Economics 125:1, 1-45.

Cohen, J., Dupas, P., and Schaner, S. (2014). "Price Subsidies, Diagnostic Tests, and Targeting of Malaria Treatment." Forthcoming American Economic Review.

Dupas, P. and Robinson, J. (2013) "Why Don't the Poor Save More? Evidence from Health Savings Experiments." American Economic Review. 103(4): 1138-1171.

Dupas, P. (2014a). Short-Run Subsidies and Long-Run Adoption of New Health Products: Evidence from a Field Experiment". Econometrica 82(1): 197-28.

Dupas, P. (2014b). "Getting essential health products to their end users: Subsidize, but how much?" Science. 35(6202): 1279-1280.

Galiani, S., Gertler, P., Orsola-Vidal, A., and Ajzenman, N. (2014). "Promoting Handwashing Behavior: The Effect of Large-Scale Community and School-Level Interventions" Working Paper.

Gertler, P, Shah, M., and Bertozzi, S. (2005) "Risky Business: The Market for Unprotected Commercial Sex," Journal of Political Economy, University of Chicago Press, 113(3):518-550.

Giné, Xavier, Dean Karlan, and Jonathan Zinman. 2010. "Put Your Money Where Your Butt Is: A Commitment Contract for Smoking Cessation." American Economic Journal: Applied Economics, 2(4): 213-35.

Grossman, M. (1972). "On the Concept of Health Capital and the Demand for Health." Journal of Political Economy, 80, No. 2 (March/April), pp. 223-255.

Guiteras, R.P., Levine, D., Luby, S., Polley, T., Kaniz Khatun-e-Jannat, K., and Unicomb, L. (2014) "Disgust and Shame: Motivating Contributions to Public Goods," Working paper, University of California Berkeley, Center for Effective Global Action.

Hammer, Jeffrey and Spears, Dean. 2013. Village sanitation and children's human capital: evidence from a randomized experiment by the Maharashtra government. Impact Evaluation series; no. IE 103; Policy Research working paper, no. WPS 6580. Washington, DC: World Bank.

Humphrey, J. H. (2009). Child undernutrition, tropical enteropathy, toilets, and handwashing. The Lancet, 374(9694), 1032-1035

Kar, K. \& Pasteur, K. (2005) Subsidy or self-respect? Community led total sanitation. An update on recent developments, IDS working paper 257, Brighton: IDS

Kar K, Chambers R (2008) Handbook on Community-Led Total Sanitation. Plan International (UK). Available: http://www.communityledtotalsanitation.org/resource/handbookcommunity-led-total-sanitation. Accessed 12 February 2013. 
Karlan, D., McConnell, M., Mullainathan, M., and Zinman, J. (2012) "Getting to the Top of Mind: How Reminders Increase Saving" Working Paper.

Levine, D., Beltramo, T., Blalock, G., and Cotterman, C. (2013) What Impedes Efficient Adoption of Products? Evidence from Randomized Variation in Sales Offers for Improved Cookstoves in Uganda." Working Paper.

Luby SP, Agboatwalla M, Painter J, Altaf A, Billhimer WL, Hoekstra RM. (2004) Effect of intensive handwashing promotion on childhood diarrhea in high-risk communities in Pakistan: a randomized controlled trial. JAMA. 291(21):2547-54.

Mara D, Lane J, Scott B, and Trouba D (2010). Sanitation and Health. PLoS Med 7(11): e1000363. doi:10.1371/journal.pmed.1000363.

Murray, C., and Lopez, A. (1997). Global mortality, disability and the contribution of risk factors: Global burden of disease study. Lancet 349: 1436-1442.

Norman G, Pedley S, Takkouche B (2010) Effects of sewerage on diarrhoea and enteric infections: a systematic review and meta-analysis. Lancet Infect Dis 10:536-544.

Oaxaca, Ronald (1973) "Male-Female Wage Differentials in Urban Labor Markets," International Economic Review, 14(3): 693-709.

Patil, S. R., Arnold, B. F., Salvatore, A., Briceno, B., Colford Jr, J. M., \& Gertler, P. J. (2013). A randomized, controlled study of a rural sanitation behavior change program in Madhya Pradesh, India. World Bank Policy Research Working Paper, (6702).

Patil, S. R., Arnold, B. F., Salvatore, A., Briceno, B., Colford Jr, J. M., \& Gertler, P. J. (2014). The Effect of India's Total Sanitation Campaign on Defecation Behaviors and Child Health in Rural Madhya Pradesh: A Cluster Randomized Controlled Trial. PLOS Medicine DOI: 10.1371

Sah S., and Negussie, A (2009). "Community led total sanitation (CLTS): Addressing the challenges of scale and sustainability in rural Africa" Desalination. 248(15):666 - 672.

Spears, Dean. 2012. "Effects of Rural Sanitation on Infant Mortality and Human Capital: Evidence from India's Total Sanitation Campaign." working paper, Princeton.

Tarozzi, A., Mahajan, A., Blackburn, B., Kopf, D., Krishnan, L., and Yoong, J., (2014). " Microloans, Insecticide-Treated Bednets, and Malaria: Evidence from a Randomized Controlled Trial in Orissa, India," American Economic Review, American Economic Association, vol. 104(7), pages 1909-41.

Thaler, R.H., and Sunstein, C.R. (2008) Nudge: Improving Decisions about Health, Wealth, and Happiness. Yale University Press.

UNICEF, WHO (2012) World Health Organization and United Nations Children's Fund Joint Monitoring Programme for Water Supply and Sanitation (JMP). Progress on Drinking Water and Sanitation: 2012 Update. New York and Geneva: UNICEF and WHO. 
Wells, C. D. S. and Sijbesma, C (2012) "Practical innovations for strengthening Community-Led Total Sanitation: selected experience from Asia, Development in Practice, 22(3): 417426.

WHO Multicentre Growth Reference Study Group. (2006). WHO Child Growth Standards: Length/Height-for-age, Weight-for-Age, Weight-for-Length, Weight-for-Height and Body Mass Index-for-Age: Methods and Development. Geneva: World Health Organization.

WHO Multicentre Growth Reference Study Group. (2007). WHO Child Growth Standards: Head Circumference-for-Age, Arm Circumference-for-Age, Triceps Skinfold-for-Age and Subscapular Skinfold-for-Age: Methods and Development. Geneva: World Health Organization.

Ziegelbauer, K., Speich, B.,et al. (2012). Effect of sanitation on soil-transmitted helminth infection: systematic review and meta-analysis. PLoS medicine, 9(1), e1001162. 
Table 1: Experimental Design and Data

\begin{tabular}{|c|c|c|c|c|}
\hline & India & Indonesia & Mali & Tanzania \\
\hline Geographic Location & $\begin{array}{l}2 \text { rural Districts in } \\
\text { Madhya Pradesh }\end{array}$ & $\begin{array}{c}8 \text { rural Districts in } \\
\text { East Java }\end{array}$ & $\begin{array}{c}\text { Province of } \\
\text { Koulikoro }\end{array}$ & $\begin{array}{l}10 \text { rural Districts } \\
\text { all over country }\end{array}$ \\
\hline Random Assignment & yes & yes & yes & yes \\
\hline Unit of Assignment & Village & Village & Village & Village \\
\hline Stratification & Block & Subdistrict & None & District \\
\hline Treatment Group Compliance & $100 \%$ & $66 \%$ & $98 \%$ & $84 \%$ \\
\hline Control Group Contamination & $25 \%$ & $14 \%$ & $10 \%$ & $0 \%$ \\
\hline Average Exposure period & 6 months & 24 months & 18 months & 23 months \\
\hline Date Baseline Survey & May-July 2009 & Aug-Sept 2008 & April-July 2011 & None \\
\hline Date Endline Survey & Feb-April 2011 & Nov 2010-Jan 2011 & April-June 2013 & May-Dec 2012 \\
\hline Number of Villages & 80 & 160 & 121 & 90 \\
\hline Number of Households & 1,655 & 1,908 & 7,461 & 1,800 \\
\hline Number of Children under 5 & 2046 & 2300 & 6745 & $\mathrm{~N} / \mathrm{A}$ \\
\hline Treatment Attrition Rate & $7.9 \%$ & $4.4 \%$ & $6.1 \%$ & $N / A$ \\
\hline Control Attrition Rate & $7.4 \%$ & $4.1 \%$ & $6.4 \%$ & $\mathrm{~N} / \mathrm{A}$ \\
\hline
\end{tabular}

Sources: For India see Patil et al (2013 and 2014). For Indonesia see Cameron and Shah (2010) and Cameron, Shah and Olivia (2013). For Mali see Aluza et al (2014). For Tanzania see Martinez et al (2014). 
Table 2: Intervention Design by Country

\begin{tabular}{cccc}
\hline Country & \# of CLTS Visits to Communities & $\begin{array}{c}\text { Subsidy for } \\
\text { construction }\end{array}$ & $\begin{array}{c}\text { Strengthen Supply of } \\
\text { Construction Materials } \\
\text { and Skilled Masons }\end{array}$ \\
\hline India & One CLTS visit & Yes \\
Indonesia & $\begin{array}{c}\text { One CLTS visit with one follow-up } \\
\text { visit to reinforce messages } \\
\text { Mali }\end{array}$ & No & No \\
& follow-up visit to reinforce messages \\
Tanzania & One CLTS visits with one follow-up \\
visit to reinforce messages & No & No & No \\
\hline
\end{tabular}

Sources: For India see Patil et al (2013 and 2014). For Indonesia see Cameron and Shah (2010) and Cameron, Shah and Olivia (2013). For Mali see Aluza et al (2014). For Tanzania see Martinez et al (2014). 
Table 3: Impact of Treatment on Open Defecation

\begin{tabular}{|c|c|c|c|}
\hline & (1) & (2) & (3) \\
\hline & Full Sample & $\begin{array}{c}\text { Households with } \\
\text { Private Sanitation at } \\
\text { Baseline }\end{array}$ & $\begin{array}{c}\text { Households without } \\
\text { Private Sanitation at } \\
\text { Baseline }\end{array}$ \\
\hline \multicolumn{4}{|l|}{ Indonesia } \\
\hline Treatment & $\begin{array}{l}-0.030 \\
{[0.027]}\end{array}$ & $\begin{array}{c}0.005 \\
{[0.014]}\end{array}$ & $\begin{array}{c}-0.077 * * * \\
{[0.029]}\end{array}$ \\
\hline Sample Size & 1,899 & 962 & 937 \\
\hline Control Mean & 0.409 & 0.087 & 0.760 \\
\hline \multicolumn{4}{|l|}{ India } \\
\hline Treatment & $\begin{array}{c}-0.090 * * * \\
{[0.031]}\end{array}$ & $\begin{array}{c}0.029 \\
{[0.042]}\end{array}$ & $\begin{array}{c}-0.091 * * * \\
{[0.020]}\end{array}$ \\
\hline Sample Size & 1,655 & 202 & 1,453 \\
\hline Control Mean & 0.859 & 0.177 & 0.947 \\
\hline \multicolumn{4}{|l|}{ Mali } \\
\hline Treatment & $\begin{array}{c}-0.328^{* * *} \\
{[0.036]}\end{array}$ & $\begin{array}{c}-0.211 * * * \\
{[0.023]}\end{array}$ & $\begin{array}{c}-0.385 * * * \\
{[0.041]}\end{array}$ \\
\hline Sample Size & 3,981 & 1,383 & 2,598 \\
\hline Control Mean & 0.568 & 0.365 & 0.679 \\
\hline \multicolumn{4}{|l|}{ Tanzania } \\
\hline Treatment & $\begin{array}{c}-0.125 * * * \\
{[0.028]}\end{array}$ & $\begin{array}{c}0.007 \\
{[0.006]}\end{array}$ & $\begin{array}{c}-0.135 * * * \\
{[0.034]}\end{array}$ \\
\hline Sample Size & 1,786 & 467 & 1,319 \\
\hline Control Mean & 0.233 & 0.005 & 0.299 \\
\hline
\end{tabular}

Notes: This table reports the estimated effect of treatment on the household's degree of open defecation. Each panel represents a different sample and each column a different specification. Each treatment effect comes from a separate linear regression. See tables in the appendix for baseline balance results. Indonesia regressions include sub-district fixed effects, India block fixed effects, and Tanzania district fixed effects. Robust standard errors are clustered at the village level in Indonesia, India, Mali and Tanzania; these are reported in brackets below the treatment effects. ${ }^{* * *} p<0.01, * * p<0.05, * p<0.1$. 
Table 4: Impact of Treatment on Access to Sanitation Facilities, Among Households Without Private Sanitation Facilities at Baseline

\begin{tabular}{|c|c|c|c|}
\hline & (1) & $(2)$ & (3) \\
\hline & Any Sanitation & Private Sanitation & Shared Sanitation \\
\hline \multicolumn{4}{|l|}{ Indonesia } \\
\hline Treatment & $\begin{array}{c}0.076 * * * \\
{[0.023]}\end{array}$ & $\begin{array}{l}0.043 * * \\
{[0.017]}\end{array}$ & $\begin{array}{l}0.034 * \\
{[0.018]}\end{array}$ \\
\hline Sample Size & 937 & 937 & 937 \\
\hline Control Mean & 0.163 & 0.080 & 0.095 \\
\hline \multicolumn{4}{|l|}{ India } \\
\hline Treatment & $\begin{array}{c}0.238 * * * \\
{[0.037]}\end{array}$ & $\begin{array}{c}0.236 * * * \\
{[0.034]}\end{array}$ & $\begin{array}{c}0.003 \\
{[0.006]}\end{array}$ \\
\hline Sample Size & 1,453 & 1,453 & 1,453 \\
\hline Control Mean & 0.141 & 0.133 & 0.008 \\
\hline \multicolumn{4}{|l|}{ Mali } \\
\hline Treatment & $\begin{array}{c}0.390 * * * \\
{[0.029]}\end{array}$ & $\begin{array}{c}0.381 * * * \\
{[0.029]}\end{array}$ & $\begin{array}{c}0.009 * * \\
{[0.004]}\end{array}$ \\
\hline Sample Size & 2,639 & 2,639 & 2,639 \\
\hline Control Mean & 0.146 & 0.141 & 0.005 \\
\hline \multicolumn{4}{|l|}{ Tanzania } \\
\hline Treatment & $\begin{array}{c}0.134^{* * *} \\
{[0.034]}\end{array}$ & $\begin{array}{c}0.153^{* * *} \\
{[0.029]}\end{array}$ & $\begin{array}{c}-0.019 \\
{[0.027]}\end{array}$ \\
\hline Sample Size & 1,323 & 1,323 & 1,323 \\
\hline Control Mean & 0.702 & 0.372 & 0.330 \\
\hline
\end{tabular}

Notes: This table reports the estimated effect of treatment on the probability that the household has access to any sanitation facility, a private facility on their property, and a shared public or private facility not on their property. Each panel represents a different sample and each column a different specification. Each treatment effect comes from a separate linear regression. See tables in the appendix for baseline balance results. Indonesia regressions include sub-district fixed effects, India block fixed effects, and Tanzania district fixed effects. Robust standard errors are clustered at the village level in Indonesia, India, Mali, and Tanzania; these are reported in brackets below the treatment effects. ${ }^{* * *} p<0.01, * * p<0.05, * p<0.1$. 
Table 5: Decomposition of Treatment Impacts on Open Defecation, Households Without Private Sanitation at Baseline

\begin{tabular}{|c|c|c|c|c|c|}
\hline & $\begin{array}{l}\text { Treatment } \\
\qquad\left(\lambda_{1}\right)\end{array}$ & $\begin{array}{c}\text { Private } \\
\text { Sanitation } \\
\left(\lambda_{2}\right)\end{array}$ & $\begin{array}{c}(\text { Treatment }) \times \\
\text { (Private Sanitation) } \\
\left(\lambda_{3}\right)\end{array}$ & $\begin{array}{l}\text { Sample } \\
\text { Size }\end{array}$ & $\begin{array}{c}\text { Control } \\
\text { Mean }\end{array}$ \\
\hline \multicolumn{6}{|c|}{ Panel A: No Controls } \\
\hline Indonesia & $\begin{array}{c}-0.064^{* *} \\
{[0.029]}\end{array}$ & $\begin{array}{c}-0.613^{* * *} \\
{[0.056]}\end{array}$ & $\begin{array}{c}0.107 \\
{[0.073]}\end{array}$ & 937 & 0.760 \\
\hline India & $\begin{array}{c}-0.004 \\
{[0.010]}\end{array}$ & $\begin{array}{c}-0.372 * * * \\
{[0.063]}\end{array}$ & $\begin{array}{c}0.001 \\
{[0.075]}\end{array}$ & 1,453 & 0.947 \\
\hline Mali & $\begin{array}{c}-0.361 * * * \\
{[0.047]}\end{array}$ & $\begin{array}{c}-0.291^{* * *} \\
{[0.042]}\end{array}$ & $\begin{array}{c}0.148 * * * \\
{[0.056]}\end{array}$ & 2,544 & 0.685 \\
\hline Tanzania & $\begin{array}{c}-0.108^{* *} \\
{[0.047]}\end{array}$ & $\begin{array}{c}-0.363^{* * *} \\
{[0.039]}\end{array}$ & $\begin{array}{c}0.056 \\
{[0.054]}\end{array}$ & 1,319 & 0.299 \\
\hline \multicolumn{6}{|c|}{ Panel B: With Controls } \\
\hline Indonesia & $\begin{array}{c}-0.059 * * \\
{[0.028]}\end{array}$ & $\begin{array}{c}-0.578 * * * \\
{[0.056]}\end{array}$ & $\begin{array}{c}0.109 \\
{[0.0737]}\end{array}$ & 937 & .760 \\
\hline India & $\begin{array}{c}0.006 \\
{[0.012]}\end{array}$ & $\begin{array}{c}-0.328 * * * \\
{[0.060]}\end{array}$ & $\begin{array}{l}-0.034 \\
{[0.072]}\end{array}$ & 1,453 & 0.947 \\
\hline Mali & $\begin{array}{c}-0.353 * * * \\
{[0.043]}\end{array}$ & $\begin{array}{c}-0.276 * * * \\
{[0.042]}\end{array}$ & $\begin{array}{c}0.143 * * * \\
{[0.054]}\end{array}$ & 2,377 & 0.688 \\
\hline Tanzania & $\begin{array}{c}-0.095 * * \\
{[0.045]}\end{array}$ & $\begin{array}{c}-0.368 * * * \\
{[0.037]}\end{array}$ & $\begin{array}{c}0.047 \\
{[0.053]}\end{array}$ & 1,317 & 0.298 \\
\hline
\end{tabular}

Notes: This table reports the estimated effects on the household's degree of open defecation. Each panel represents a different sample and each column a different specification. Each treatment effect comes from a separate linear regression. The set of controls in the Indonesia models in Panel B include the age, gender and education of the household head, household size, the natural log of household per capita income at baseline, whether the household had a dirt floor at baseline, whether the village is within a ten-minute walk from a river, risk tolerance, a discount rate, and an indicator of the randomization block. The controls for India in Panel B are baseline indicators of whether any caregiver in the household had correct knowledge about diarrhea, whether any caregiver in the household had correct knowledge about risks of open defecation, age and sex of household head, dummies for primary-secondary-higher secondary+ education levels of the household head, whether the household belonged to a marginalized caste (SCST), whether household is below poverty line as per their ration card (official document), number of members in the household, wealth index, and natural log of monthly household income. The set of controls for Mali in Panel B are age, gender, literacy of the household head, reported household size at baseline, language spoken in the household (dummy=1 if Bambara is the main language), asset index, OD disapproval and an index of social capital. The set of controls for Tanzania in Panel B are household head sex, age, and years of education, household size, household wealth, material for the floor of the main living area is made of earth or clay, and whether the respondent knows OD causes animals to become sick. Robust standard errors are clustered at the village level in Indonesia, India, Mali, and Tanzania; these are reported in in brackets below the treatment effects. *** $p<0.01, * * p<0.05, * p<0.1$. 
Table 6: Decomposition of Treatment on OD Into Behavioral and Investment Pathways

\begin{tabular}{|c|c|c|c|c|c|c|c|}
\hline & \multicolumn{4}{|c|}{ Behavioral Change (OD) } & \multicolumn{2}{|c|}{$\begin{array}{c}\text { Investment Effect } \\
\text { (Private In-home Sanitation } \\
\text { Construction) }\end{array}$} & \multirow{2}{*}{$\begin{array}{c}\begin{array}{c}\text { Total } \\
\text { Change }\end{array} \\
\text { All }\end{array}$} \\
\hline & \multicolumn{2}{|c|}{$\begin{array}{l}\text { Households With Private } \\
\text { In-home Sanitation }\end{array}$} & \multicolumn{2}{|c|}{$\begin{array}{l}\text { Households Without Private } \\
\text { In-home Sanitation }\end{array}$} & \multicolumn{2}{|c|}{$\begin{array}{l}\text { Households Without Private } \\
\text { In-home Sanitation }\end{array}$} & \\
\hline & $d \pi(D \mid S=1)[\pi(S)]$ & $\begin{array}{c}\% \text { of } \\
\text { Total } \Delta\end{array}$ & $\begin{array}{c}d \pi(D \mid S=0) \times \\
{[1-\pi(S)]}\end{array}$ & $\begin{array}{l}\% \text { of } \\
\text { Total } \Delta\end{array}$ & $\begin{array}{l}d \pi(S)[\pi(D \mid S=1) \\
-\pi(D \mid S=0)]\end{array}$ & $\begin{array}{c}\% \text { of } \\
\text { Total } \Delta\end{array}$ & $=d \pi(D)$ \\
\hline Indonesia & Not Significant & $(0.0 \%)$ & $-0.064 \times 0.877=-0.056$ & $(71.8 \%)$ & $0.043 \times-0.506=-0.022$ & $(28.2 \%)$ & -0.078 \\
\hline India & Not Significant & $(0.0 \%)$ & Not Significant & $(0.0 \%)$ & $0.236 \times-0.371=-0.088$ & $(100 \%)$ & -0.088 \\
\hline Mali & $-0.211 \times 0.522=-0.110$ & $(32.6 \%)$ & $-0.361 \times 0.478=-0.173$ & $(51.3 \%)$ & $0.381 \times-0.143=-0.054$ & $(16.1 \%)$ & -0.337 \\
\hline Tanzania & Not Significant & $(0.0 \%)$ & $-0.108 \times 0.475=-0.051$ & $(52 \%)$ & $0.153 \times-0.307=-0.047$ & $(48 \%)$ & -0.098 \\
\hline
\end{tabular}


Table 7. Effect of Village Open Defecation on Child Height for Age z-scores

\begin{tabular}{|c|c|c|c|c|}
\hline & (1) & $(2)$ & (3) & (4) \\
\hline & \multicolumn{2}{|c|}{ OLS } & \multicolumn{2}{|c|}{ IV GMM } \\
\hline & $\begin{array}{c}\text { No } \\
\text { Controls }\end{array}$ & Controls & $\begin{array}{c}\text { No } \\
\text { Controls }\end{array}$ & Controls \\
\hline \multicolumn{5}{|l|}{ Panel A: Child Height z-score } \\
\hline Village Open Defecation & $\begin{array}{c}-0.420 * * * \\
{[0.116]}\end{array}$ & $\begin{array}{c}-0.341 * * * \\
{[0.120]}\end{array}$ & $\begin{array}{c}-0.460 * * * \\
{[0.159]}\end{array}$ & $\begin{array}{c}-0.344 * * \\
{[0.159]}\end{array}$ \\
\hline Sample Size (individuals) & 5,600 & 5,600 & 5,600 & 5,600 \\
\hline Sample Size (villages) & 318 & 318 & 318 & 318 \\
\hline Control Mean & -1.813 & -1.813 & -1.813 & -1.813 \\
\hline \multicolumn{5}{|l|}{ Panel B: First Stage } \\
\hline Treatment India & & & $\begin{array}{c}0.221 * * * \\
{[0.038]}\end{array}$ & $\begin{array}{c}0.214 * * * \\
{[0.037]}\end{array}$ \\
\hline Treatment Indonesia & & & $\begin{array}{c}0.011 \\
{[0.030]}\end{array}$ & $\begin{array}{l}-0.001 \\
{[0.027]}\end{array}$ \\
\hline Treatment Mali & & & $\begin{array}{c}-0.254 * * * \\
{[0.064]}\end{array}$ & $\begin{array}{c}- \\
0.247^{* * *} \\
{[0.056]}\end{array}$ \\
\hline \multirow[t]{2}{*}{ Treat $\mathrm{x}$ (Share HHs w/ San in Vil at BL) $\mathrm{x}$ India } & & & $\begin{array}{c}-0.497^{* * *} \\
{[0.059]}\end{array}$ & $\begin{array}{c}-.489 * * * \\
{[0.059]}\end{array}$ \\
\hline & & & & - \\
\hline Treat $\mathrm{x}$ (Share $\mathrm{w} /$ San in Vil at BL) $\mathrm{x}$ Indonesia & & & $\begin{array}{c}-0.914 * * * \\
{[0.131]}\end{array}$ & $\begin{array}{c}0.858 * * * \\
{[0.122]}\end{array}$ \\
\hline Treat x (Share HHs w/ San in Vil at BL) x Mali & & & $\begin{array}{c}-0.207^{*} \\
{[0.119]}\end{array}$ & $\begin{array}{c}-0.184^{*} \\
{[0.108]}\end{array}$ \\
\hline Kleibergen-Paap Wald F-Statistic & & & 6210.1 & 2913.7 \\
\hline
\end{tabular}

Notes: This table reports the estimated effect of village OD on child height for age z-scores. All regressions are estimated using pooled samples of children under 5 at baseline for India, Indonesia, and Mali. Columns 1-2 report results from OLS regressions and columns 3-4 report results from GMM IV regressions. There are six instruments for village OD: treatment in each country (3) and sanitation coverage at baseline at the village level interacted with treatment (3). Columns 1 and 3 only include controls for baseline height of the child, country and an indicator of the randomization block. Columns 2 and 4 further include a separate set of controls all measured at baseline for each country interacted with a country dummy. The Indonesia controls include child age and sex dummies, education of the household head, household size, household per capita income, dirt floor, village is within a tenminute walk from a river, and discount rate. The India controls for controls include age and sex dummies, improved water source, hand washing station with soap and water, caregiver had correct knowledge about diarrhea, caregiver had correct knowledge about risks of open defecation, age and sex of household head, household size, and household income. The Mali controls include child age and sex dummies, education and language spoken by the household head, OD disapproval, asset index, and social capital index. Robust standard errors are clustered at the village level and are reported in brackets below the main effects. ${ }^{* * *} p<0.01,{ }^{* *} p<0.05$, $* p<0.1$. 
Table 8. Impact of Treatment on Child Height for Age Z-score

\begin{tabular}{rccc}
\hline & $(1)$ & $(2)$ & $(3)$ \\
\cline { 2 - 4 } & Indonesia & India & Mali \\
\hline Treatment & -0.0118 & 0.025 & $0.174^{* *}$ \\
& {$[0.0405]$} & {$[0.104]$} & {$[0.076]$} \\
Sample Size & 1,919 & 1,286 & 2,182 \\
Control Mean & -1.725 & -1.782 & -1.725 \\
\hline
\end{tabular}

Notes: This table reports the estimated effect of treatment on the height for age z-scores. Each treatment effect comes from a separate linear regression. All models include controls for baseline z-score, age and sex dummies, and randomization strata fixed effects. Robust standard errors are clustered at the village level and are reported in brackets below the treatment effects. ${ }^{* * *} p<0.01,{ }^{* *} p<0.05,{ }^{*} p<0.1$. 


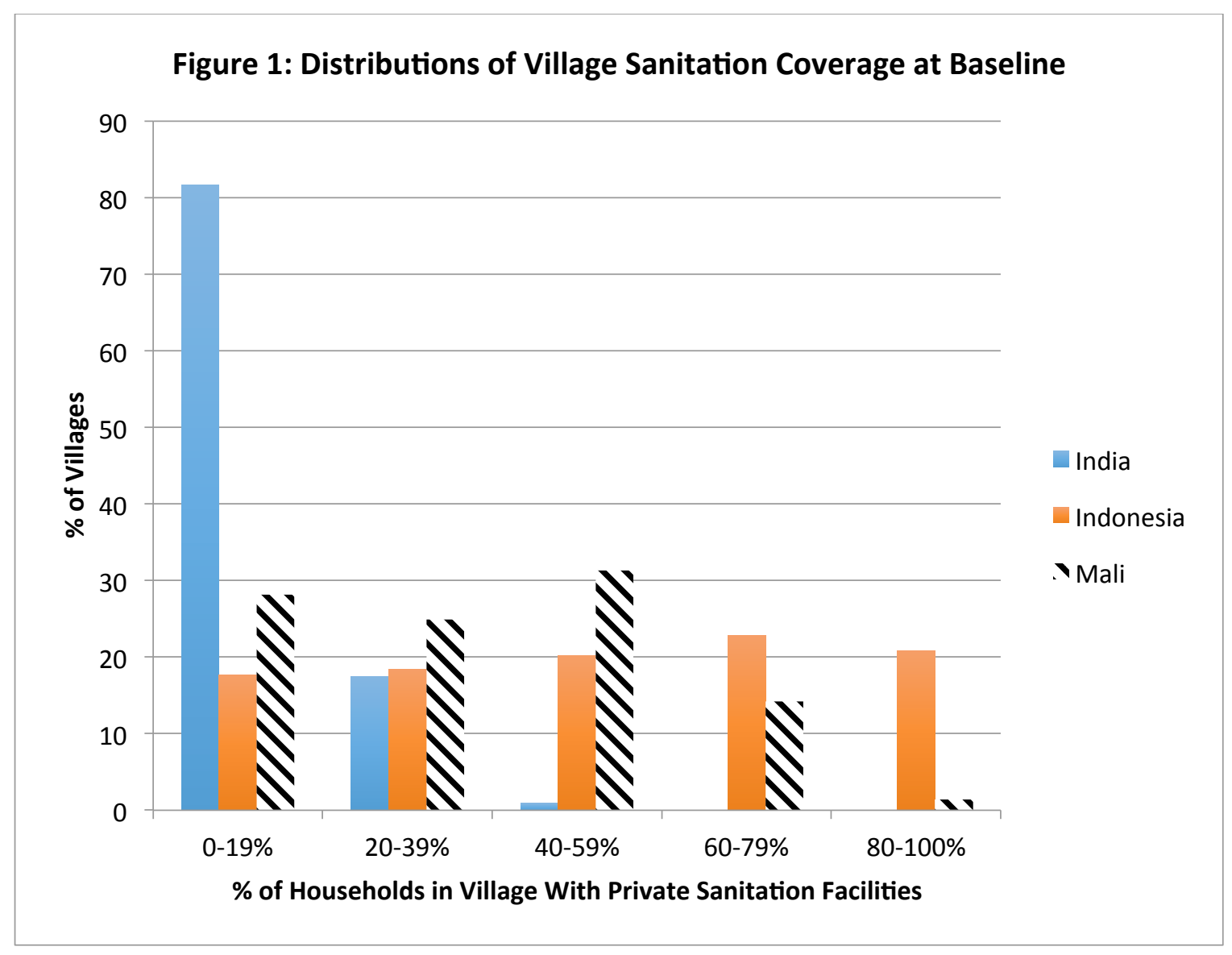


Figure 2: Distributions of Village Open Defecation Rates at Endline

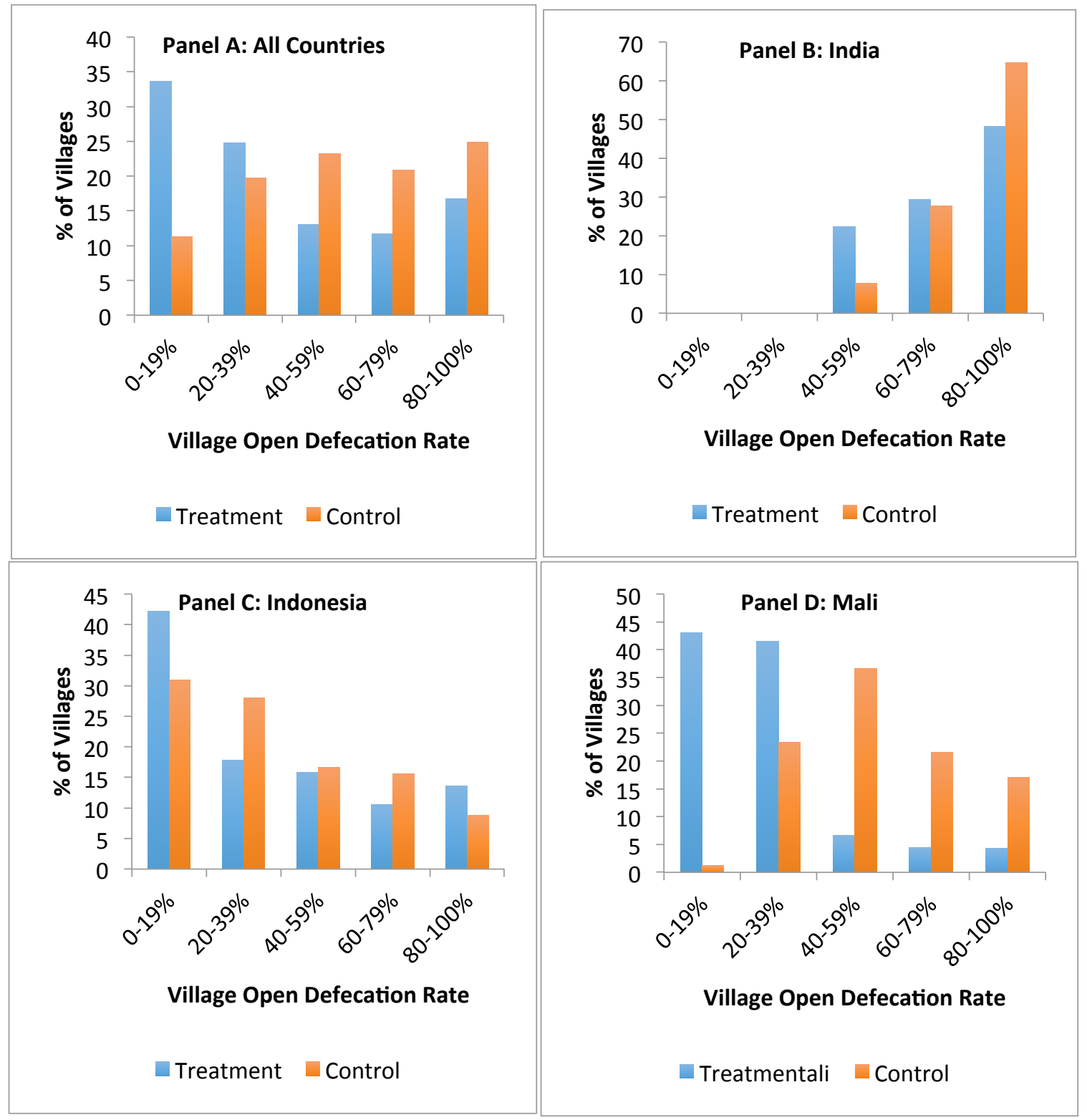


Figure 3: Nonparametric Regression of Child Height for Age z-scores on Village OD Rate

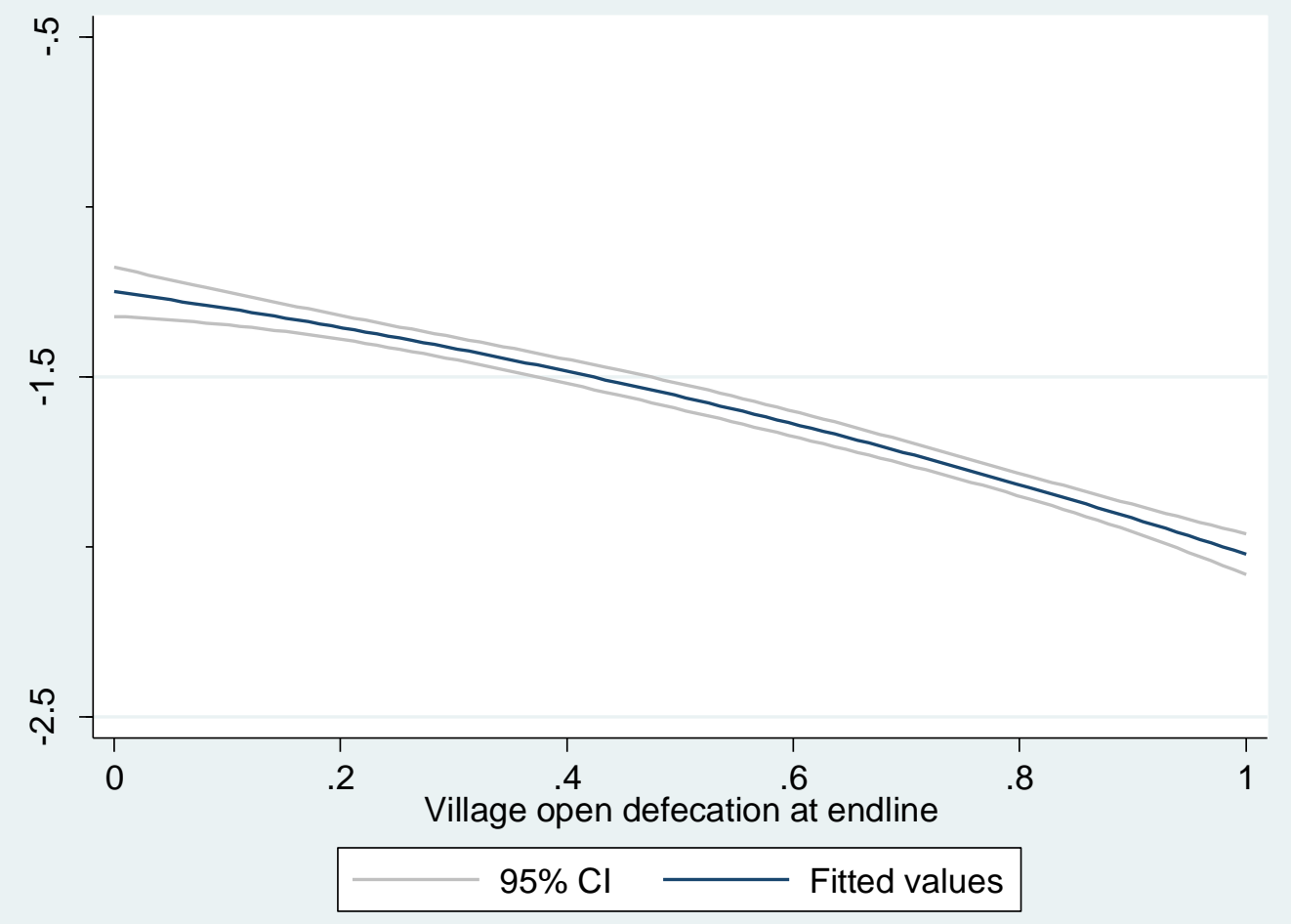




\section{Appendix: Experimental Design and Data}

\section{Sample Selection and Randomization}

The data used in this paper were generated from cluster-randomized interventions in all four countries. The unit of randomization was the village in all four countries. In 3 out of the 4 countries, the villages were first clustered into strata and then the villages were randomized into treatment and control groups within each stratum. The data used are from baseline and follow-up surveys of households with children under 2 years of age. In general, the samples for all four countries appear to be well balanced at baseline, have low levels of attrition, and show little evidence of attrition bias. The details of the random assignment and data collection are presented in Table 1 and discussed in the data appendix.

The evaluation occurred in eight districts of rural East Java, Indonesia; in 2 districts in Madhya Pradesh, India; the region of Koulikoro in Mali, and 10 districts in Tanzania. The strata used for random assignment are sub-districts in Indonesia, blocks in India, and districts in Tanzania. There were no stratifications used in Mali. Detailed information on sample selection and randomization can be found for each country in Cameron and Shah (2010), Cameron et al. (2013), Patil et al. (2013), Alzua et al. (2014), and Briceño et al. (2014).

In Indonesia, during the study period, trained facilitators went into the eight project districts and supported the local governments in conducting triggering and follow-up activities in the communities. Of the 80 treatment villages, the endline survey data shows that 53 villages (66 percent) were triggered. ${ }^{4}$ Approximately $14 \%$ of control villages were triggered. Initial sample size calculations indicate that this level of non-compliance was not sufficient to underpower our results.

In India, two districts in Madhya Pradesh participated in the impact evaluation of TSC (Dhar and Khargone), for a total of 80 rural villages. One hundred percent of the treatment villages received the program. Based on interviews with block level Total Sanitation Campaign (TSC) officers, all treatment GPs received at least some funds with more than half receiving $100 \%$ of the allocated budget for TSC. Block officers also reported that 10 of the 40 control villages ( 25\%) received the TSC program.

For the case of Mali, $100 \%$ of the treatment communities received the program and 59 out of 60 communities achieved Open Defecation Free Certification. While 10 percent of the control communities reported to have received some program for constructing latrines, they do not mention Unicef or the Malian Government. The team was not aware of any other NGOs promoting sanitation in the region of the study at that time, but some local churches and advocacy groups may be present to promote improved sanitation.

\footnotetext{
${ }^{4}$ This means that one or more of the four community leaders surveyed (village head, community head, health cadre, head of women's organization, or other community leader) reported that the village had received a triggering.
} 
Tanzania is administratively separated into 30 Regions, 169 Districts and 3643 Wards, with the average ward holding approximately 12,000 people. The sample was drawn from 10 districts spread throughout the country selected by the Ministry of Water (MoW) and Ministry of Health and Social Welfare (MoHSW) to provide geographic diversity at the national level. To evaluate the impact of TSSM, a cluster-randomized evaluation with random assignment of interventions at the ward level was implemented (including 44 treatment and 46 control wards). Wards were identified as the optimal operational unit of implementation for the project, and of sufficient geographic extension to minimize the risk of significant information spillovers between populations exposed to the localized messages, community events, and other forms of social promotion activities. Program reports suggest that $86 \%$ of wards were triggered with TSSM activities and that there was no contamination into control areas.

\section{Data Collection}

The data collection efforts focused on households with children under 2 years of age as young children's health is affected the most by poor sanitation (Murray and Lopez, 1997). All countries used similar and standardized structured questionnaires, but questionnaires were also modified to suit the local research needs. The survey collected data on social and demographic characteristics of the household and its members, information on household income, assets and labor force activity, household infrastructure and services for sanitation, hygiene and water, major housing facilities and amenities, and child school attendance and care. The survey also elicited the sanitation and hygiene knowledge, attitudes, and practices of the main caregivers of children under 5 years. The health survey recorded recent illness for children under 5 years and anthropometric measurements.

In Indonesia, the baseline survey was conducted in both treatment and control communities in August - September 2008. A total of 2,087 households with 2,353 children under 5 years in 160 sub-villages were interviewed. The sample frame of households with at least one child under 2 years was determined by lists provided by the community health cadre in each sub-village. Thirteen households were then randomly selected from this listing to participate in the baseline survey. The follow-up data collection was conducted approximately 24 months later, between November 2010 and February 2011. The endline survey used the same field methodology as the baseline survey. The final sample size in the endline survey included 1,908 households from the baseline survey with no significant differential attrition between treatment and control groups.

In India, the baseline survey was conducted in May-July 2009. From the 80 villages we completed surveys of 1954 households. The survey firm listed and mapped households in each village with information on whether they had a child under 2 years. From the list of eligible households, 25 households were randomly selected by the supervisor of the survey team using systematic random sampling. The follow up survey was conducted in February-April $2011-21$ months after the baseline survey. The final sample size in the endline survey included 1655 households from the baseline survey with 2046 children, again with no significant differential attrition between the treatment and control groups. 
For Mali, baseline information was collected between April and July 2011. A census was conducted in all 121 communities and all households with children under 10 where interviewed. A total of 4532 households were interviewed at baseline. The follow up survey took place between April and June 2013 and a total of 4031 households could be matched to the ones present in the baseline. Finally, children with complete anthropometric measures matched at baseline and follow up total approximately 2619.

Tanzania lacks a baseline survey and only had endline data. Although a baseline data collection was intended, unanticipated problems with reliability of data resulted in the cancelation of field work in five out of the 10 districts originally planned and the impossibility of using the data to validate the randomized design, as it was originally planned. However, an endline survey was conducted in 2012. Sample size details are given in Table 1.

\section{Tests of Balance and Attrition}

Randomization aims to minimize systematic differences between the control and treatment groups. However, the extent of sample attrition and the degree to which attrition is nonrandom is a legitimate concern in any follow-up survey. In India, of the 1,954 households surveyed at the baseline, 299 were lost and 1,655 were surveyed in the follow-up survey (15\% attrition). The sample loss was not differential by the treatment (154) and control (145) groups. Patil et al. (2013) show that the attrition was also not differential by the treatment and control groups based on several important characteristics and that the baseline samples are well balanced between treatment and control villages. The few variables that were not balanced at the baseline are adjusted for in our analysis.

In Indonesia, of 2,087 households interviewed at the baseline 8.5 percent households were lost and 1,908 households were successfully re-interviewed at the follow up survey. The loss was similar in treatment and control villages; 86 households in the control and 93 households in the treatment group. Cameron and Shah (2010) show that baseline sample was well balanced and Cameron et al. (2013) report that attrition did not result in significant imbalance in important household characteristics between treatment and control villages. The few variables that were imbalanced at the baseline are adjusted for in our analysis

For Mali, 4532 households were present at baseline and $12.5 \%$ were either lost or could not be matched to the ones in the baseline. In the follow up, 5206 households were interviewed, 4031 were matched to baseline ones. The loss does not differ between treatment and control groups and that attrition did not produced imbalance. (Alzua et al 2014).

Tests of balance and attrition for Tanzania are challenging since there was no baseline survey. However, we show balance for a combination of time-invariant indicators and retrospective responses asked in the endline dating to February 2009, before the intervention had started. Table A4 suggests fairly good balance. Differential attrition due to migration or other causes could also be a concern. However, data from the complete census listings of selected 
enumerator areas provide evidence of limited migration and attrition. Less than $5 \%$ of households moved into the community within the three year intervention period, and this does not differ across treatment/control groups. We mitigate any confounding that migration may cause by restricting the sample to households residing in the area since 2009. 
Table A1: INDONESIA BALANCE TABLE

\begin{tabular}{|c|c|c|c|c|c|c|c|c|c|}
\hline \multirow[b]{2}{*}{ Variables } & \multicolumn{3}{|c|}{ With Sanitation at BL } & \multicolumn{3}{|c|}{ No Sanitation at BL } & \multicolumn{3}{|c|}{ All Households } \\
\hline & $\begin{array}{l}\text { Mean } \\
\text { (Treat) }\end{array}$ & $\begin{array}{c}\text { Mean } \\
\text { (Control) }\end{array}$ & p-value & $\begin{array}{c}\text { Mean } \\
\text { (Treat) }\end{array}$ & $\begin{array}{c}\text { Mean } \\
\text { (Control) }\end{array}$ & p-value & $\begin{array}{l}\text { Mean } \\
\text { (Treat) }\end{array}$ & $\begin{array}{c}\text { Mean } \\
\text { (Control) }\end{array}$ & p-value \\
\hline Height-for-Age Z-score for children under 5 & -1.704 & -1.691 & 0.529 & -1.993 & -1.865 & 0.458 & -1.849 & -1.718 & 0.294 \\
\hline Weigh for children under 5 & 8.28 & 8.22 & 0.595 & 8.15 & 8.25 & 0.365 & 8.21 & 8.23 & 0.817 \\
\hline Household has private sanitation facility & 0.858 & 0.815 & 0.071 & 0 & 0 & - & 0.421 & 0.425 & 0.857 \\
\hline Household knows causes of diarrhea & 0.159 & 0.135 & 0.287 & 0.091 & 0.079 & 0.506 & 0.124 & 0.110 & 0.265 \\
\hline Household has good OD knowledge & 0.648 & 0.630 & 0.567 & 0.452 & 0.453 & 0.988 & 0.540 & 0.555 & 0.511 \\
\hline Household size & 5.030 & 5.0181 & 0.898 & 4.820 & 4.626 & 0.035 & 4.923 & 4.831 & 0.162 \\
\hline Age of household head & 41.39 & 41.80 & 0.567 & 39.69 & 38.974 & 0.304 & 40.53 & 40.45 & 0.875 \\
\hline Male household head & 0.933 & 0.946 & 0.422 & 0.956 & 0.976 & 0.139 & 0.946 & 0.960 & 0.151 \\
\hline Child is male & 0.478 & 0.515 & 0.239 & 0.517 & 0.507 & 0.755 & 0.490 & 0.497 & 0.728 \\
\hline Household head completed primary & 0.426 & 0.376 & 0.117 & 0.602 & 0.598 & 0.904 & 0.515 & 0.482 & 0.149 \\
\hline Household head completed secondary & 0.206 & 0.233 & 0.314 & 0.193 & 0.189 & 0.878 & 0.200 & 0.212 & 0.497 \\
\hline Household head completed higher-secondary & 0.316 & 0.348 & 0.294 & 0.137 & 0.138 & 0.946 & 0.225 & 0.248 & 0.239 \\
\hline Log per capita income & 14.70 & 14.70 & 0.973 & 14.15 & 14.15 & 0.939 & 14.42 & 14.44 & 0.724 \\
\hline Household is poor & 0.146 & 0.123 & 0.269 & 0.348 & 0.367 & 0.554 & 0.251 & 0.239 & 0.574 \\
\hline Household has dirt floor & 0.146 & 0.185 & 0.106 & 0.320 & 0.343 & 0.448 & 0.234 & 0.261 & 0.188 \\
\hline River runs through village & 0.690 & 0.640 & 0.098 & 0.782 & 0.796 & 0.615 & 0.737 & 0.714 & 0.266 \\
\hline Risk tolerant & 0.185 & 0.150 & 0.045 & 0.160 & 0.169 & 0.644 & 0.172 & 0.156 & 0.244 \\
\hline Discount rate & 0.601 & 0.584 & 0.282 & 0.609 & 0.601 & 0.652 & 0.604 & 0.592 & 0.321 \\
\hline
\end{tabular}


Table A2: INDIA BALANCE TABLES

\begin{tabular}{|c|c|c|c|c|c|c|c|c|c|}
\hline \multirow[b]{2}{*}{ Variables } & \multicolumn{3}{|c|}{ With Sanitation at BL } & \multicolumn{3}{|c|}{ No Sanitation at BL } & \multicolumn{3}{|c|}{ All Households } \\
\hline & $\begin{array}{c}\text { Mean } \\
\text { (Treat) }\end{array}$ & $\begin{array}{c}\text { Mean } \\
\text { (Control) }\end{array}$ & p-value & $\begin{array}{c}\text { Mean } \\
\text { (Treat) } \\
\end{array}$ & $\begin{array}{c}\text { Mean } \\
\text { (Control) }\end{array}$ & p-value & $\begin{array}{c}\text { Mean } \\
\text { (Treat) } \\
\end{array}$ & $\begin{array}{c}\text { Mean } \\
\text { (Control) }\end{array}$ & p-value \\
\hline Child had diarrhea in last 7 days & 0.097 & 0.063 & 0.238 & 0.140 & 0.129 & 0.608 & 0.132 & 0.121 & 0.582 \\
\hline Mean Height-for-Age Z-score for under 5 children & -1.312 & -1.736 & 0.117 & -1.457 & -1.854 & 0.057 & -1.391 & -1.803 & 0.056 \\
\hline Household reports OD as main sanitation option & 0.238 & 0.174 & 0.280 & 0.900 & 0.865 & 0.510 & 0.816 & 0.790 & 0.641 \\
\hline Household reports having improved sanitation & 0.731 & 0.798 & 0.276 & 0.043 & 0.029 & 0.327 & 0.136 & 0.123 & 0.685 \\
\hline$\%$ of HHs in GP with improved Sanitation facility & 0.253 & 0.289 & 0.513 & 0.117 & 0.097 & 0.459 & 0.136 & 0.123 & 0.688 \\
\hline$\%$ of HHs in GP with improved water source & 0.921 & 0.865 & 0.156 & 0.887 & 0.773 & 0.027 & 0.892 & 0.797 & 0.037 \\
\hline$\%$ of HHs in GP wi soap/water at hand-washing station & 0.570 & 0.692 & 0.049 & 0.429 & 0.531 & 0.118 & 0.444 & 0.540 & 0.126 \\
\hline Age in months of the child under 5 years & 22.03 & 22.219 & 0.874 & 21.71 & 22.104 & 0.461 & 21.88 & 22.120 & 0.603 \\
\hline Age of household Head & 51.24 & 52.716 & 0.487 & 45.18 & 41.889 & 0.006 & 45.33 & 43.179 & 0.054 \\
\hline Male household head & 0.938 & 0.954 & 0.580 & 0.937 & 0.958 & 0.077 & 0.940 & 0.948 & 0.508 \\
\hline Household head attended school & 0.811 & 0.829 & 0.739 & 0.461 & 0.509 & 0.301 & 0.499 & 0.527 & 0.537 \\
\hline Household head completed primary school & 0.095 & 0.133 & 0.305 & 0.117 & 0.123 & 0.756 & 0.108 & 0.124 & 0.378 \\
\hline Household head completed secondary school & 0.619 & 0.562 & 0.295 & 0.304 & 0.339 & 0.410 & 0.341 & 0.347 & 0.883 \\
\hline Household Head completed higher-secondary school & 0.087 & 0.133 & 0.318 & 0.036 & 0.043 & 0.547 & 0.045 & 0.052 & 0.549 \\
\hline Primary care giver knows the causes of diarrhea & 0.705 & 0.697 & 0.910 & 0.667 & 0.640 & 0.418 & 0.680 & 0.659 & 0.455 \\
\hline Household belongs to schedule caste/tribe & 0.333 & 0.284 & 0.563 & 0.729 & 0.769 & 0.466 & 0.697 & 0.714 & 0.762 \\
\hline House construction is robust (pucca) & 0.823 & 0.899 & 0.068 & 0.543 & 0.562 & 0.721 & 0.571 & 0.604 & 0.489 \\
\hline Log monthly household income & 4.150 & 4.179 & 0.651 & 3.878 & 3.877 & 0.991 & 3.843 & 3.862 & 0.506 \\
\hline
\end{tabular}




\begin{tabular}{|c|c|c|c|c|c|c|c|c|c|}
\hline \multirow[b]{2}{*}{ Variables } & \multicolumn{3}{|c|}{ With Sanitation at BL } & \multicolumn{3}{|c|}{ No Sanitation at BL } & \multicolumn{3}{|c|}{ All Households } \\
\hline & $\begin{array}{l}\text { Mean } \\
\text { (Treat) }\end{array}$ & $\begin{array}{c}\text { Mean } \\
\text { (Control) }\end{array}$ & p-value & $\begin{array}{l}\text { Mean } \\
\text { (Treat) }\end{array}$ & $\begin{array}{l}\text { Mean } \\
\text { (Control) }\end{array}$ & p-value & $\begin{array}{l}\text { Mean } \\
\text { (Treat) }\end{array}$ & $\begin{array}{l}\text { Mean } \\
\text { (Control) }\end{array}$ & p-value \\
\hline Mean Height-for-Age Z-score for under 5 children & -1.206 & -1.175 & 0.609 & -1.391 & -1.460 & 0.382 & -1.265 & -1.267 & 0.975 \\
\hline Mean Weight-for-Age Z-score for under 5 children & -1.130 & -1.102 & 0.712 & -1.290 & -1.346 & 0.515 & -1.181 & -1.180 & 0.991 \\
\hline Age in months of the child under 5 years & 26.861 & 27.184 & 0.425 & 26.554 & 26.276 & 0.578 & 26.763 & 26.891 & 0.711 \\
\hline Household reports OD as sanitation option & 0.895 & 0.884 & 0.572 & 0.995 & 0.978 & $0.040 * *$ & 0.930 & 0.917 & 0.375 \\
\hline Household reports OD as main sanitation option & 0.882 & 0.852 & 0.183 & 0.982 & 0.969 & 0.310 & 0.916 & 0.893 & 0.177 \\
\hline Household knows dirty place causes diarrhea & 0.795 & 0.718 & $0.002 * * *$ & 0.721 & 0.734 & 0.788 & 0.769 & 0.724 & $0.075^{*}$ \\
\hline Believes OD is Not Acceptable & 0.780 & 0.789 & 0.705 & 0.618 & 0.709 & $0.097^{*}$ & 0.724 & 0.761 & 0.188 \\
\hline OD is Not Acceptable in Community & 0.431 & 0.548 & $0.017^{* *}$ & 0.875 & 0.889 & 0.690 & 0.585 & 0.666 & 0.138 \\
\hline Household size (self-reported) & 7.997 & 8.109 & 0.708 & 6.776 & 6.877 & 0.692 & 7.564 & 7.677 & 0.656 \\
\hline Household is poor (lowest p(25)) & 0.155 & 0.187 & 0.184 & 0.442 & 0.433 & 0.897 & 0.279 & 0.305 & 0.503 \\
\hline Household is poor (if sum of assets $<30 \%$ ) & 0.038 & 0.051 & 0.333 & 0.167 & 0.193 & 0.609 & 0.097 & 0.114 & 0.481 \\
\hline Household is poor (if sum of assets $<35 \%$ ) & 0.101 & 0.130 & 0.180 & 0.359 & 0.345 & 0.835 & 0.212 & 0.229 & 0.630 \\
\hline Household is poor (if sum of assets $<40 \%$ ) & 0.155 & 0.187 & 0.184 & 0.442 & 0.433 & 0.897 & 0.279 & 0.305 & 0.496 \\
\hline Literacy (household head) & 0.356 & 0.365 & 0.792 & 0.212 & 0.221 & 0.823 & 0.306 & 0.314 & 0.799 \\
\hline Male household head & 0.969 & 0.973 & 0.568 & 0.963 & 0.954 & 0.518 & 0.967 & 0.966 & 0.926 \\
\hline Age of household head & 44.264 & 44.350 & 0.912 & 42.694 & 43.015 & 0.730 & 43.703 & 43.880 & 0.792 \\
\hline
\end{tabular}


Table A4: TANZANIA BALANCE TABLE (ENDLINE DATA WITH RETROSPECTIVE VARIABLES)

\begin{tabular}{|c|c|c|c|c|c|c|c|c|c|}
\hline \multirow{2}{*}{ Variables } & \multicolumn{3}{|c|}{ With Sanitation at BL } & \multicolumn{3}{|c|}{ No Sanitation at BL } & \multicolumn{3}{|c|}{ All Households } \\
\hline & $\begin{array}{l}\text { Mean } \\
\text { (Treat) }\end{array}$ & $\begin{array}{c}\text { Mean } \\
\text { (Control) }\end{array}$ & p-value & $\begin{array}{l}\text { Mean } \\
\text { (Treat) }\end{array}$ & $\begin{array}{c}\text { Mean } \\
\text { (Control) }\end{array}$ & p-value & $\begin{array}{l}\text { Mean } \\
\text { (Treat) }\end{array}$ & $\begin{array}{c}\text { Mean } \\
\text { (Control) }\end{array}$ & p-value \\
\hline A household member owns the dwelling & 0.912 & 0.927 & 0.448 & 0.936 & 0.920 & 0.277 & 0.899 & 0.910 & 0.505 \\
\hline Clean lighting energy (electricity, solar, gas) & 0.049 & 0.065 & 0.491 & 0.029 & 0.029 & 0.963 & 0.050 & 0.053 & 0.829 \\
\hline Electricity as main lighting energy source & 0.019 & 0.040 & 0.318 & 0.015 & 0.010 & 0.494 & 0.027 & 0.029 & 0.865 \\
\hline Paraffin lamps main lighting source & 0.799 & 0.759 & 0.360 & 0.764 & 0.685 & $0.046^{* *}$ & 0.781 & 0.695 & $0.016^{* *}$ \\
\hline Floor of main living area made of cement & 0.193 & 0.213 & 0.554 & 0.097 & 0.096 & 0.93 & 0.149 & 0.148 & 0.964 \\
\hline Floor of main living area made of earth/clay & 0.800 & 0.765 & 0.318 & 0.896 & 0.872 & 0.26 & 0.843 & 0.825 & 0.487 \\
\hline Male & 0.886 & 0.829 & $0.028 * *$ & 0.900 & 0.890 & 0.435 & 0.883 & 0.866 & 0.125 \\
\hline Age & 41.392 & 41.034 & 0.691 & 39.520 & 39.618 & 0.866 & 40.123 & 39.960 & 0.730 \\
\hline Ever attended school & 0.816 & 0.808 & 0.758 & 0.772 & 0.719 & $0.078 *$ & 0.793 & 0.757 & $0.085^{*}$ \\
\hline Can read and write & 0.796 & 0.759 & 0.269 & 0.717 & 0.671 & 0.13 & 0.752 & 0.709 & $0.058 *$ \\
\hline Years of Education (if attended school) & 5.254 & 5.172 & 0.711 & 4.927 & 4.598 & 0.119 & 5.099 & 4.903 & 0.209 \\
\hline Muslim & 0.352 & 0.336 & 0.67 & 0.290 & 0.244 & 0.148 & 0.321 & 0.273 & 0.112 \\
\hline Christian & 0.598 & 0.624 & 0.489 & 0.614 & 0.601 & 0.699 & 0.607 & 0.611 & 0.895 \\
\hline HH size & 5.055 & 4.994 & 0.709 & 5.012 & 4.948 & 0.683 & 4.991 & 4.896 & 0.412 \\
\hline Age of child when first cared by caregivers & 0.082 & 0.052 & 0.252 & 0.101 & 0.084 & 0.431 & 0.089 & 0.077 & 0.361 \\
\hline Piped water main source of drinking water & 0.125 & 0.116 & 0.813 & 0.099 & 0.047 & $0.003 * * *$ & 0.113 & 0.079 & 0.134 \\
\hline Well main source of drinking water & 0.323 & 0.408 & 0.154 & 0.303 & 0.352 & 0.335 & 0.314 & 0.372 & 0.207 \\
\hline Surface water main source of drinking water & 0.370 & 0.339 & 0.602 & 0.411 & 0.466 & 0.264 & 0.383 & 0.418 & 0.436 \\
\hline $\mathrm{HH}$ treats their water & 0.385 & 0.391 & 0.888 & 0.400 & 0.360 & 0.233 & 0.407 & 0.375 & 0.28 \\
\hline Wealth index & 0.169 & 0.165 & 0.793 & -0.409 & 0.137 & 0.216 & -0.349 & 0.098 & 0.192 \\
\hline Owns another house & 0.179 & 0.187 & 0.783 & 0.137 & 0.128 & 0.596 & 0.162 & 0.144 & 0.181 \\
\hline
\end{tabular}


